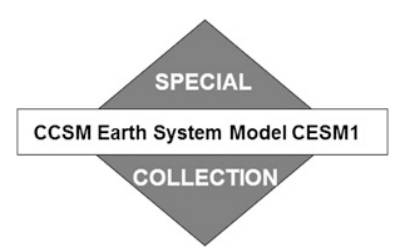

\title{
Atmospheric Carbon Dioxide Variability in the Community Earth System Model: Evaluation and Transient Dynamics during the Twentieth and Twenty-First Centuries
}

\author{
Gretchen KePpel-Aleks, ${ }^{*}$ James T. RAnderson, ${ }^{*}$ Keith Lindsay ${ }^{+}$Britton B. Stephens, ${ }^{+}$ \\ J. Keith Moore,* Scott C. Doney, ${ }^{\#}$ Peter E. Thornton,${ }^{@}$ Natalie M. Mahowald, ${ }^{\&}$

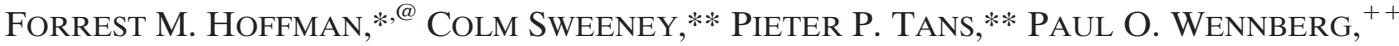 \\ AND STEVEN C. WOFSY\# \\ * Department of Earth System Science, University of California, Irvine, California \\ ${ }^{+}$National Center for Atmospheric Research, Boulder, Colorado \\ \# Woods Hole Oceanographic Institution, Woods Hole, Massachusetts \\ @ Oak Ridge National Laboratory, Oak Ridge, Tennessee \\ \& Cornell University, Ithaca, New York \\ ** Cooperative Institute for Environmental Sciences, University of Colorado, Boulder, Colorado \\ ${ }^{++}$California Institute of Technology, Pasadena, California \\ \#\# Harvard University, Cambridge, Massachusetts
}

(Manuscript received 31 July 2012, in final form 19 December 2012)

\begin{abstract}
Changes in atmospheric $\mathrm{CO}_{2}$ variability during the twenty-first century may provide insight about ecosystem responses to climate change and have implications for the design of carbon monitoring programs. This paper describes changes in the three-dimensional structure of atmospheric $\mathrm{CO}_{2}$ for several representative concentration pathways (RCPs 4.5 and 8.5) using the Community Earth System Model-Biogeochemistry (CESM1BGC). $\mathrm{CO}_{2}$ simulated for the historical period was first compared to surface, aircraft, and column observations. In a second step, the evolution of spatial and temporal gradients during the twenty-first century was examined. The mean annual cycle in atmospheric $\mathrm{CO}_{2}$ was underestimated for the historical period throughout the Northern Hemisphere, suggesting that the growing season net flux in the Community Land Model (the land component of CESM) was too weak. Consistent with weak summer drawdown in Northern Hemisphere high latitudes, simulated $\mathrm{CO}_{2}$ showed correspondingly weak north-south and vertical gradients during the summer. In the simulations of the twenty-first century, CESM predicted increases in the mean annual cycle of atmospheric $\mathrm{CO}_{2}$ and larger horizontal gradients. Not only did the mean north-south gradient increase due to fossil fuel emissions, but east-west contrasts in $\mathrm{CO}_{2}$ also strengthened because of changing patterns in fossil fuel emissions and terrestrial carbon exchange. In the RCP8.5 simulation, where $\mathrm{CO}_{2}$ increased to 1150 ppm by 2100 , the CESM predicted increases in interannual variability in the Northern Hemisphere midlatitudes of up to $60 \%$ relative to present variability for time series filtered with a $2-10-y r$ bandpass. Such an increase in variability may impact detection of changing surface fluxes from atmospheric observations.
\end{abstract}

\section{Introduction}

Carbon dioxide is a dominant anthropogenic greenhouse gas in the earth's atmosphere. Its atmospheric concentration has risen from $280 \mathrm{ppm}$ preindustrially to 390 ppm in 2011 because of fossil fuel combustion and land use change (R. F. Keeling et al. 1996; Prentice et al.

Corresponding author address: Gretchen Keppel-Aleks, Department of Earth System Science, University of California, Irvine, 2230 Croul Hall, Irvine CA 92697.

E-mail: g.keppelaleks@uci.edu
2000). The extent to which $\mathrm{CO}_{2}$ levels in the atmosphere continue increasing will be the primary determinant of future climate change (Solomon et al. 2007). The trajectory of atmospheric $\mathrm{CO}_{2}$ depends not only on humanmediated fluxes, such as those from fossil fuel combustion or land use change, but also on the response of the natural carbon cycle to changing atmospheric composition and climate (Fung et al. 2005). Currently, 55\% of $\mathrm{CO}_{2}$ emitted by human activities is taken up by the ocean or terrestrial ecosystems, with $45 \%$ remaining airborne (Le Quéré et al. 2009). The degree to which the efficiency of these sinks will change with climate is an 
open question, with implications for the rate of atmospheric accumulation. Therefore, prediction of future climate is closely linked to prediction of carbon cycle dynamics (Friedlingstein et al. 2006).

Numerous studies have documented the responses of terrestrial and oceanic fluxes of carbon to changes in the physical climate system (e.g., Sarmiento and Gruber 2002). Carbon-climate interactions operate on multiple time scales; for instance, drought and high temperature stress can reduce carbon uptake by terrestrial ecosystems over continental-scale regions (Ciais et al. 2005; Phillips et al. 2009) and can trigger increases in biomass burning (e.g., Golding and Betts 2008; Chen et al. 2011) on interannual time scales. Observations of atmospheric $\mathrm{CO}_{2}$ indicate that the atmospheric growth rate varies substantially from year to year owing to interannual climate modes, such as the El Niño-Southern Oscillation, and their impact on ocean and terrestrial biosphere fluxes (Bacastow 1976; Rayner et al. 1999; Jones et al. 2001; Schwalm et al. 2011). On decadal time scales, increases in westerly winds over the Southern Ocean may have weakened the net ocean uptake of $\mathrm{CO}_{2}$ over the last three decades (Le Quéré et al. 2007; Lovenduski et al. 2008). In terrestrial ecosystems, lengthening of the growing season in high northern latitudes has increased carbon dioxide uptake in spring and early summer (C. D. Keeling et al. 1996; Randerson et al. 1999), but also carbon release in the early fall (Piao et al. 2008). The carbon losses from these ecosystems are likely caused by increases in soil temperature that may contribute to permafrost thaw and degradation (e.g., Schuur et al. 2009; Koven et al. 2011).

Global climate models have developed over time to include more Earth system processes that feedback onto the climate. With the development of Earth system models (ESMs), interactions between the carbon cycle and the climate system are represented through multiple pathways, enabling the study of climate-carbon feedbacks (e.g., Thornton et al. 2009; Arora and Montenegro 2011). These models allow us to estimate likely $\mathrm{CO}_{2}$ levels that correspond to particular fossil fuel emission pathways and to better represent uncertainty in climate projections resulting from carbon cycle processes. Important challenges in this regard are evaluating ESM performance and understanding how biases in model structure influence future projections.

Here, we developed several new approaches for evaluating the three-dimensional structure of $\mathrm{CO}_{2}$ in earth system models. Atmospheric $\mathrm{CO}_{2}$ is an integrator of surface fluxes, and its variations on seasonal and longer time scales reflect the terrestrial and oceanic processes that control carbon-climate feedbacks (Randerson et al. 2009; Cadule et al. 2010). Although $\mathrm{CO}_{2}$ perturbations in the atmosphere persist long enough to be well mixed in terms of radiative forcing, small horizontal and vertical gradients in atmospheric $\mathrm{CO}_{2}$ allow for the diagnosis of regional to continental-scale sources and sinks (e.g., Gurney et al. 2002). Carbon dioxide is emitted and removed largely at the surface, but simulation of atmospheric mixing near the surface is challenging because of difficulties in representing boundary layer and convective processes and the impacts of topographic variations in atmospheric models. As a consequence, simulation of vertical and horizontal mixing of $\mathrm{CO}_{2}$ varies considerably among different models, and this has important implications for our understanding of $\mathrm{CO}_{2}$, including the magnitude of sources and sinks (Gurney et al. 2002; Stephens et al. 2007; Yang et al. 2007).

In this study, we analyzed the three-dimensional structure of atmospheric $\mathrm{CO}_{2}$ in one example of such coupled models, the Community Earth System Model (CESM). In the version of CESM used here (CESM1-BGC), atmospheric $\mathrm{CO}_{2}$ is represented as a three-dimensional atmospheric tracer, which, in the simulations described here, influenced the atmospheric radiation budget and thus top-of-the-atmospheric energy fluxes (Lindsay et al. 2012, manuscript submitted to J. Climate). Variability of $\mathrm{CO}_{2}$ in the model is controlled by the geographic and seasonal distribution of natural and anthropogenic surface fluxes as well as by different atmospheric transport processes such as advection, convection, and eddy mixing.

We evaluated the performance of the CESM against several types of atmospheric $\mathrm{CO}_{2}$ data measured from different platforms, each of which has a different measurement footprint and is therefore impacted by fluxes and transport differently. We used the following datasets: surface flask and in situ data from the NOAA Global Monitoring Division (GMD) (Conway et al. 1994) and the Scripps Institution of Oceanography (SIO) (Keeling et al. 2001), column-average mole fraction observations from the Total Carbon Column Observing Network (TCCON) (Wunch et al. 2011), and aircraft data obtained from both the High-Performance Instrumented Airborne Platform for Environmental Research (HIAPER) Pole-to-Pole Observations (HIPPO) campaigns (Wofsy et al. 2011) and GMD and Department of Energy (DOE) long-term monitoring stations. In our analysis, we examined seasonal cycles in $\mathrm{CO}_{2}$, vertical and horizontal gradients, and interannual variability, along with multidecadal trends in these datasets. These comparisons were used to infer how accurately the CESM reproduces spatial and temporal variations in fluxes, which in turn provides a means to gauge the realism of future projections by the model for representative concentration pathways (RCPs) (Moss et al. 2010). 
In the second part of this paper, we analyzed simulations of twenty-first-century $\mathrm{CO}_{2}$ based on the RCP scenarios developed for phase 5 of the Coupled Model Intercomparison Project (CMIP5). This analysis provides us with insight about the response of carbon fluxes to increased anthropogenic forcing and how variations in atmospheric $\mathrm{CO}_{2}$ may change in time with possible consequences for monitoring strategies. Because of interest in an international climate treaty to monitor and verify national fossil fuel emissions (National Research Council 2010), the carbon monitoring community will require observations of atmospheric $\mathrm{CO}_{2}$ that can differentiate among trajectories of $\mathrm{CO}_{2}$ emissions at subcontinental spatial scales. When considering the information that would be gained by additional observations, it is important to consider the changing background variability—such as seasonal variations and variations caused by transport acting on larger spatial gradientsin the future and how this variability influences our ability to use the network for change detection and carbon flux attribution.

This paper is structured as follows: in section 2, we describe the CESM components relevant for simulating atmospheric $\mathrm{CO}_{2}$ and the atmospheric $\mathrm{CO}_{2}$ data used for comparison with the model. In section 3 , we provide results from the comparison of simulated $\mathrm{CO}_{2}$ from the CESM with these datasets. In section 4 , we show trends in simulated $\mathrm{CO}_{2}$ for two RCP scenarios. In section 5, we discuss the implications of our comparisons for model development, carbon cycle science, and future atmospheric monitoring strategies.

\section{Methods}

\section{a. Community Earth System Model}

We analyzed simulations from CESM1-BGC, a fully coupled general circulation model with atmosphere, ocean, land, and sea ice components. CESM was developed from model components in the Community Climate System Model version 4 (CCSM4) (Gent et al. 2011). For the purposes of this study, the most significant change with CESM was that the carbon cycle was completely prognostic: feedbacks between the simulated climate and terrestrial and oceanic fluxes of $\mathrm{CO}_{2}$ determined the atmospheric concentration used in the radiative scheme. More details on the biogeochemistry coupling are found in Lindsay et al. (2012, manuscript submitted to J. Climate).

The atmospheric component of CESM is the Community Atmospheric Model (CAM), version 4 (Neale et al. 2013). CAM 4 used a finite volume dynamical core and has an improved parameterization of deep convection relative to its predecessors (Gent et al. 2011). Interannual variability due to El Niño was better captured than in previous versions (Deser et al. 2012), and variables such as land surface temperature and precipitation that affect terrestrial carbon cycling also showed less bias (P. J. Lawrence et al. 2012). For the simulations analyzed here, CAM 4 was run at $0.9^{\circ}$ latitude $\times 1.25^{\circ}$ longitude horizontal resolution and had 26 vertical layers arranged in a hybrid pressure sigma coordinate. The total $\mathrm{CO}_{2}$ dry air mole fraction ( parts per million) and the dry air mole fraction of the components of $\mathrm{CO}_{2}$ owing to fossil fuel fluxes, land exchange, and ocean exchange were each tracked separately in the model. We primarily analyzed monthly mean CESM output, but used daily mean $\mathrm{CO}_{2}$ for the comparisons with atmospheric aircraft data.

The Community Land Model (CLM) version 4 was the basis for terrestrial ecosystem fluxes of $\mathrm{CO}_{2}$ (D. M. Lawrence et al. 2012). Like previous versions of the land model, CLM4 simulated fluxes of energy and water between the atmosphere and land surface. This newest version included a carbon-nitrogen $(\mathrm{C}-\mathrm{N})$ cycle model that is prognostic in carbon and nitrogen fluxes and in vegetation phenology (Thornton et al. 2007). In the experiments that we analyzed, plant functional types were prescribed, and land-use change fluxes were simulated following the approach described by P. J. Lawrence et al. (2012). The imposed land-use change fluxes are in good agreement with Global Carbon Project (GCP) estimates (Canadell et al. 2007) between 1970 and 1999. For this time period, the GCP estimated a $1.5 \pm 0.5$ $\mathrm{Pg} \mathrm{C} \mathrm{yr}^{-1}$ land use source of $\mathrm{CO}_{2}$ to the atmosphere, while

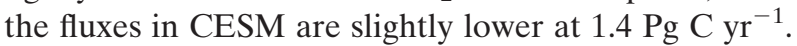
Global soil carbon from CLM4 was $514 \mathrm{Pg} \mathrm{C}$, which is approximately a factor of 2 lower than the $1255 \mathrm{Pg} \mathrm{C}$ estimate from the Harmonized World Soil Database (HWSD) (Todd-Brown et al. 2013). At high northern latitudes, the low bias in CLM4 was even greater: by a factor of 5 compared to HWSD and by over a factor of 8 compared to the Northern Circumpolar Soil Carbon Database. Global net primary production levels were approximately $52 \mathrm{Pg} \mathrm{C} \mathrm{yr}^{-1}$, comparable to remote sensing-derived estimates (Todd-Brown et al. 2013). At high northern latitudes, gross primary production (GPP) from CLM4 was approximately the same as observations from FLUXNET, although in the tropics there was a significant positive bias (Bonan et al. 2011). The combined soil carbon and productivity estimates from CLM indicated that soil organic turnover times in the model were likely too small, with rapid carbon cycling contributing to the low bias in soil carbon stocks. We also note that the CESM runs analyzed here did not include dynamic vegetation changes, which may have 
limited the magnitude of simulated changes in regional carbon fluxes during the twenty-first century simulations.

The ocean model influenced atmospheric $\mathrm{CO}_{2}$ in CESM by physical uptake and transport of $\mathrm{CO}_{2}$ in overturning water masses and through ocean biogeochemistry. The ocean physical model is described in detail in Danabasoglu et al. (2011). Briefly, the ocean model was run at $1^{\circ}$ horizontal resolution with 60 vertical layers. Ocean dynamics were based on the Parallel Ocean Program, version 2 (Smith et al. 2010). The ocean biogeochemical model was the Biogeochemical Element Cycle (BEC) model developed for the CCSM (Moore et al. 2004; Moore and Braucher 2008; Doney et al. 2009). There were few modifications to the model for the CESM implementation (for details see Lindsay et al. 2012, manuscript submitted to J. Climate; Moore et al. 2012, manuscript submitted to J. Climate). Air-sea $\mathrm{CO}_{2}$ exchange during the twentieth century is described by Long et al. (2013).

We analyzed output from a CESM simulation that followed the historical CMIP5 protocol. The simulation began in 1850 and ended in 2005. Anthropogenic fossil fuel emissions, based on national emission estimates from the Carbon Dioxide Information Analysis Center (CDIAC) (Boden et al. 2009), were prescribed with a $1^{\circ}$ spatial resolution and monthly time step (Andres et al. 2011). Transient aerosol emissions also were specified, following time series developed by Lamarque et al. (2010). As described above, exchange of $\mathrm{CO}_{2}$ between the land and atmosphere and ocean and atmosphere was fully coupled within the model. As a result, atmospheric $\mathrm{CO}_{2}$ responded prognostically to fossil and land use change fluxes.

We also analyzed variations in twenty-first century $\mathrm{CO}_{2}$ from two CESM simulations that followed different RCP scenarios (Moss et al. 2010; van Vuuren et al. 2011). The RCP4.5 scenario corresponds to a nominal anthropogenic radiative forcing of $4.5 \mathrm{~W} \mathrm{~m}^{-2}$ at 2100 and assumes stabilization of emissions by the middle of the twenty-first century. To achieve emissions reductions and radiative forcing stabilization of $4.5 \mathrm{~W} \mathrm{~m}^{-2}$, the scenario assumes international participation in emissions mitigation and a common global price for emissions of $\mathrm{CO}_{2}$ and other greenhouse gases that cover all sectors of the economy (Thomson et al. 2011). The RCP8.5 scenario corresponds to nominal anthropogenic radiative forcing of $8.5 \mathrm{~W} \mathrm{~m}^{-2}$ at 2100 and assumes steady population growth with continuing high energy demand and little investment in energy technology, leading to reliance on local and high-carbon-content fuels (Riahi et al. 2011). These simulations began in the year 2005, with initial conditions provided by the historical simulation described above, and were run to 2100 . Fossil fuel emission trajectories consistent with the nominal radiative forcing

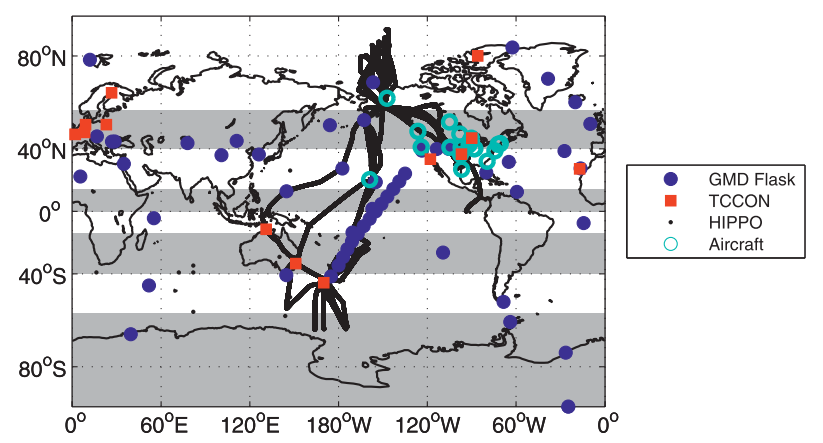

FIG. 1. Locations of observations used in this paper: CESM at Global Monitoring Division (GMD) flask sites (blue circles), TCCON observatories (red squares), NOAA aircraft profile locations (cyan circles), and along HIPPO flight tracks (black dots). The alternating zonal color bands demark the regions used for averaging the data: $60^{\circ}-90^{\circ} \mathrm{S}, 40^{\circ}-60^{\circ} \mathrm{S}, 15^{\circ}-40^{\circ} \mathrm{S}, 0^{\circ}-15^{\circ} \mathrm{S}, 0^{\circ}-15^{\circ} \mathrm{N}$, $15^{\circ}-40^{\circ} \mathrm{N}, 40^{\circ}-60^{\circ} \mathrm{N}$, and $60^{\circ}-90^{\circ} \mathrm{N}$.

for these two scenarios were developed using two different integrated assessment models (IAMs) (van Vuuren et al. 2011). The regionally aggregated emissions generated by the IAMs were regridded at monthly resolution by T. Nozawa from the Asian-Pacific Integrated Model (AIM) modeling team at the National Institute for Environmental Studies in Japan by scaling the spatial and seasonal patterns for year 2005 fluxes (e.g., Andres et al. 2011). This regridding process accounted for $\mathrm{CO}_{2}$ emissions from international ships. As such, the spatial and seasonal distribution of emissions may differ from emissions used by other modeling centers for the same CMIP5 experiments, and the seasonal dynamics and finescale spatial structure represent only one possible scenario of fossil fuel emission patterns consistent with the RCP time series. Because the interactive carbon fluxes and aerosol parameterizations in CESM differed from those in the IAMs used to devise the emissions pathways, the resulting radiative forcing differed from the nominal RCP value at 2100 .

\section{b. Carbon dioxide observations}

We used several data sources to evaluate simulated atmospheric $\mathrm{CO}_{2}$, including surface, column, and aircraft measurements (Fig. 1). The surface, column, and aircraft observations spanned all latitudes, but several geographic areas were under represented (e.g., Africa and the Amazon). For ease in comparing the observations with the model, we binned the data into the eight latitude zones shown by alternating color bands in Fig. 1 and listed in Table 1.

For surface $\mathrm{CO}_{2}$ data, we compared CESM to NOAA GMD flask and Scripps in situ observations. The NOAA data record consisted of weekly flasks sampled in a global cooperative network (Fig. 1, Table 1). These data 
are compatible to within $0.2 \mathrm{ppm}$ of the WMO $\mathrm{CO}_{2}$ scale (WMO 2011), with a precision of $\pm 0.1 \mathrm{ppm}(1 \sigma)$ (Conway et al. 1994). We selected locations that had near-continuous data coverage from the mid-1990s (or earlier) to the present. We also used monthly mean atmospheric $\mathrm{CO}_{2}$ obtained in situ at the Mauna Loa (MLO) and South Pole (SPO) Observatories by the Scripps Institution of Oceanography (SIO) (Keeling et al. 2001) to compare with the atmospheric growth rate in the model from 1958 to 2010.

For each surface observation site, we sampled CESM at the gridbox containing the observatory. We sampled the model at the nearest altitude (in units of meters above sea level) to that at which observations were obtained. For one site-Baring Head, New Zealand, where observations were only made when the wind was onshore and $\mathrm{CO}_{2}$ stable - we chose a CESM gridbox $10^{\circ}$ south of the site to reflect marine background conditions. Similar approaches have been used in earlier atmospheric transport and inversion studies to account for the sampling biases introduced by coarse-resolution global model grids (e.g., Law et al. 2010). We did not use modified sampling locations for other sites because patterns in the shape and phasing of the mean annual cycle agreed qualitatively between CESM and the observations. We note that in our comparisons of NOAA GMD and TCCON observations, we used 24-h mean mole fractions from the model, whereas many of the observations were sampled only during the day. To avoid potential biases from this temporal sampling mismatch, we did not attempt to systematically analyze $\mathrm{CO}_{2}$ variability in the planetary boundary layer over land.

We compared total column $\mathrm{CO}_{2}$ in CESM to data obtained by TCCON observatories (Washenfelder et al. 2006; Deutscher et al. 2010; Messerschmidt et al. 2011; Wunch et al. 2011). Total column $\mathrm{CO}_{2}$ is an observation of the vertically integrated mass of $\mathrm{CO}_{2}$ above a sampling location, normalized by the dry air column to yield a vertically integrated mole fraction. As such, simulated total column $\mathrm{CO}_{2}$ is less sensitive to errors in the model's vertical mixing parameterization than surface mole fraction (Keppel-Aleks et al. 2011). Variations in total column $\mathrm{CO}_{2}$ integrate fluxes at large scales, so the observations provide little information about local fluxes and, instead provide strong constraints on hemisphericscale fluxes (Keppel-Aleks et al. 2012).

TCCON data were obtained using ground-based Fourier transform spectrometry. The data have been calibrated against aircraft profiles and are compatible with respect to the $\mathrm{WMO} \mathrm{CO}_{2}$ scale and precise to better than 0.8 ppm (1- $\sigma$ precision) (Wunch et al. 2010). Only seven TCCON sites had at least one full annual cycle of observations, although several more high northern latitude stations had obtained data during summer, when solar zenith angles permitted retrievals (Table 2). We leveraged sites without a full annual data cycle to constrain the north-south $\mathrm{CO}_{2}$ mass gradient during seasons when observations were available. We sampled CESM at the TCCON locations and integrated the simulated $\mathrm{CO}_{2}$ mole fractions to determine the total column average mole fraction, applying TCCON averaging kernels as described in Keppel-Aleks et al. (2012).

We compared free tropospheric CESM $\mathrm{CO}_{2}$ with aircraft measurements from two sources: the HIPPO campaigns (Wofsy et al. 2011) and biweekly NOAA GMD vertical profiles. Like surface $\mathrm{CO}_{2}$, observations of free tropospheric $\mathrm{CO}_{2}$ measured at a single level in the atmosphere are sensitive to the rate of vertical mixing in the model. Taken as a set, however, the relative agreement between observed and simulated $\mathrm{CO}_{2}$ at several levels have the potential to allow diagnosis of the extent to which differences are due to surface fluxes or atmospheric physics (Stephens et al. 2007; Yang et al. 2007).

We compared free tropospheric $\mathrm{CO}_{2}$ observed during the HIPPO campaign with CESM $\mathrm{CO}_{2}$. HIPPO consisted of five campaigns, with flights occurring during all seasons between 2009 and 2011 (Wofsy et al. 2011). The aircraft obtained a series of vertical profiles from the surface to $>14 \mathrm{~km}$ while flying between $87^{\circ} \mathrm{N}$ and $67^{\circ} \mathrm{S}$. Flights occurred primarily over the Pacific, although individual campaigns included excursions over, for instance, Australia or the continental United States (Fig. 1). The $\mathrm{CO}_{2}$ mole fraction was measured using several instruments aboard the NCAR Gulfstream V aircraft: two LI-COR nondispersive infrared gas analyzers, a quantum cascade laser system (QCLS), and two flask samplers. In this study, we used the composite recommended $\mathrm{CO} 2_{x}$ variable, which is almost exclusively from the QCLS instrument, and has precision of $0.02 \mathrm{ppm}$ and compatibility with respect to the World Meteorological Organization $\mathrm{CO}_{2}$ scale of $0.2 \mathrm{ppm}$.

For HIPPO, we separated each of the five campaigns into a northbound and southbound leg and binned the data from each leg into the eight north-south regions and averaged the data vertically in four layers of equal depth between the surface and $10 \mathrm{~km}$. We sampled daily mean CESM at every location where a HIPPO observation was available for five consecutive model years and averaged the model estimates using the same latitude-altitude bins.

The second set of aircraft observations consisted of biweekly to monthly profiles sampled by the NOAA Global Monitoring Division and the U.S. Department of Energy (DOE) at 19 aircraft sites in the Northern Hemisphere, primarily over North America (Fig. 1). Measurements were made between the surface and 
TABLE 1. Surface flask observations within the eight regional latitude zones used for evaluating the CESM.

\begin{tabular}{|c|c|c|c|c|c|}
\hline Region & Station & Acronym & Lat $\left({ }^{\circ} \mathrm{N}\right)$ & Lon $\left({ }^{\circ} \mathrm{E}\right)$ & Operational dates \\
\hline & \multicolumn{5}{|c|}{$60^{\circ}-90^{\circ} \mathrm{N}$} \\
\hline & Alert, Alaska & ALT & 82.5 & -62.5 & 1985-2010 \\
\hline & Barrow, Alaska & BRW & 71.3 & -156.6 & 1971-2010 \\
\hline & Storhofdl, Iceland & ICE & 63.4 & -20.3 & $1992-2010$ \\
\hline & Summit, Greenland & SUM & 72.6 & -38.4 & 1997-2010 \\
\hline & Ny-Ålesund, Svalbard & ZEP & 78.9 & 11.9 & 1994-2010 \\
\hline & \multicolumn{5}{|c|}{$40^{\circ}-60^{\circ} \mathrm{N}$} \\
\hline & Baltic Sea, Poland & BAL & 55.4 & 17.2 & 1992-2010 \\
\hline & Cold Bay, Alaska & $\mathrm{CBA}$ & 55.2 & -162.7 & 1978-2010 \\
\hline & Sary Taukum, Kazakhstan & KZD & 44.1 & 76.9 & 1997-2009 \\
\hline & Plateu Assy, Kazakhstan & $\mathrm{KZM}$ & 43.3 & 77.9 & 1997-2009 \\
\hline & Mace Head, Ireland & MHD & 53.3 & -9.9 & 1991-2010 \\
\hline & Niwot Ridge, Colorado & NWR & 40.1 & -105.6 & 1968-2010 \\
\hline & Shemya, Alaska & SHM & 52.7 & 174.1 & 1985-2010 \\
\hline & Trinidad Head, California & THD & 41.1 & -124.2 & 2002-2010 \\
\hline & Ulaan Uul, Mongolia & UUM & 44.5 & 111.1 & 1992-2010 \\
\hline & \multicolumn{5}{|c|}{$15^{\circ}-40^{\circ} \mathrm{N}$} \\
\hline & Assekrem, Algeria & ASK & 23.2 & 5.4 & 1995-2010 \\
\hline & Terceira Islands, Azores & AZR & 38.8 & -27.4 & 1979-2010 \\
\hline & Tudor Hill, Bermuda & BMW & 32.3 & -64.9 & 1989-2010 \\
\hline & Izana, Tenerife & $\mathrm{IZO}$ & 28.3 & -16.5 & 1991-2010 \\
\hline & Key Biscayne, Florida & KEY & 25.7 & -80.2 & 1972-2010 \\
\hline & Midway Island & MID & 28.2 & -177.4 & $1985-2010$ \\
\hline & Mauna Loa, Hawaii & MLO & 19.5 & -155.6 & 1969-2010 \\
\hline & Pacific Ocean $20^{\circ} \mathrm{N}$ & POCN20 & 20.0 & -141.0 & 1986-2009 \\
\hline & Pacific Ocean $25^{\circ} \mathrm{N}$ & POCN25 & 25.0 & -139.0 & 1986-2009 \\
\hline & Point Arena, California & PTA & 38.9 & -123.7 & 1999-2010 \\
\hline & Lamont, Oklahoma & SGP & 36.8 & -97.5 & 2002-2010 \\
\hline & Tae-Ahn peninsula, South Korea & TAP & 36.7 & 126.1 & 1990-2010 \\
\hline & Wendover, Utah & UTA & 39.9 & -113.7 & 1993-2010 \\
\hline & Negev Desert, Israel & WIS & 30.9 & 34.8 & 1995-2010 \\
\hline & Mt. Waliguan, China & WLG & 36.3 & 100.9 & 1990-2010 \\
\hline & \multicolumn{5}{|c|}{$0^{\circ}-15^{\circ} \mathrm{N}$} \\
\hline & Mariana Islands, Guam & GMI & 13.4 & 144.7 & 1979-2010 \\
\hline & Pacific Ocean $0^{\circ}$ & POC000 & 0.0 & -155.0 & 1987-2009 \\
\hline & Pacific Ocean $5^{\circ} \mathrm{N}$ & POCN05 & 5.0 & -151.0 & 1987-2009 \\
\hline & Pacific Ocean $10^{\circ} \mathrm{N}$ & POCN10 & 10.0 & -149.0 & 1987-2009 \\
\hline & Pacific Ocean $15^{\circ} \mathrm{N}$ & POCN15 & 15.0 & -145.0 & 1986-2009 \\
\hline & Ragged Point, Barbados & $\mathrm{RPB}$ & 13.2 & -59.4 & 1987-2010 \\
\hline & \multicolumn{5}{|c|}{$0^{\circ}-15^{\circ} \mathrm{S}$} \\
\hline & Ascension Island & ASC & -8.0 & -14.4 & 1979-2010 \\
\hline & Christmas Island & $\mathrm{CHR}$ & -10.5 & -157.2 & 1984-2010 \\
\hline & Pacific Ocean $10^{\circ} \mathrm{S}$ & POCS10 & -10.0 & -161.0 & $1987-2009$ \\
\hline & Pacific Ocean $5^{\circ} \mathrm{S}$ & POCS05 & -5.0 & -159.0 & 1987-2009 \\
\hline & Mahe Island, Seychelles & SEY & -4.7 & 55.2 & 1980-2010 \\
\hline & Tutuila, Samoa & SMO & -14.3 & -170.6 & 1973-2010 \\
\hline & Easter Island & EIC & -27.1 & -109.4 & 1994-2010 \\
\hline & Pacific Ocean $15^{\circ} \mathrm{S}$ & POCS15 & -15.0 & -171.0 & 1986-2010 \\
\hline & \multicolumn{5}{|c|}{$15^{\circ}-40^{\circ} \mathrm{S}$} \\
\hline & Pacific Ocean $20^{\circ} \mathrm{S}$ & POCS20 & -20.0 & -174.0 & 1987-2009 \\
\hline & Pacific Ocean $25^{\circ} \mathrm{S}$ & POCS25 & -25.0 & -171.0 & 1986-2009 \\
\hline & Pacific Ocean $30^{\circ} \mathrm{S}$ & POCS30 & -30.0 & -176.0 & 1986-2009 \\
\hline & Pacific Ocean $35^{\circ} \mathrm{S}$ & POCS35 & -35.0 & -180.0 & 1987-2009 \\
\hline
\end{tabular}


TABLE 1. (Continued)

\begin{tabular}{|c|c|c|c|c|c|}
\hline Region & Station & Acronym & Lat $\left({ }^{\circ} \mathrm{N}\right)$ & Lon $\left({ }^{\circ} \mathrm{E}\right)$ & Operational dates \\
\hline & \multicolumn{5}{|c|}{$40^{\circ}-60^{\circ} \mathrm{S}$} \\
\hline & Baring Head, New Zealand & BHD & -41.4 & 174.0 & 1999-2010 \\
\hline & Cape Grim, Tasmania & $\mathrm{CGO}$ & -40.7 & 144.7 & $1984-2010$ \\
\hline & Crozet Island & $\mathrm{CRZ}$ & -46.5 & 51.9 & $1991-2010$ \\
\hline & Tierra del Fuego & TDF & -54.9 & -68.3 & 1994-2010 \\
\hline & \multicolumn{5}{|c|}{$60^{\circ}-90^{\circ} \mathrm{S}$} \\
\hline & Halley Bay, Antarctica & HBA & -75.6 & -26.2 & 1983-2010 \\
\hline & Palmer Station, Antarctica & PSA & -64.9 & -64.0 & $1978-2010$ \\
\hline & South Pole & SPO & -90.0 & -24.8 & $1978-2010$ \\
\hline & Syowa, Antarctica & SYO & -69.0 & 39.6 & 1986-2010 \\
\hline
\end{tabular}

$8 \mathrm{~km}$ via automated portable flask packages aboard small aircraft. Table 3 lists the sites and the temporal coverage of the data. Like the surface flasks, the aircraft flasks were analyzed at NOAA within one week of sampling (Crevoisier et al. 2010; Biraud et al. 2013; http://www. esrl.noaa.gov/gmd/ccgg/aircraft/index.html).

\section{c. Time series analysis}

To compare CESM with observations of the annual cycle, we detrended both the observations and CESM using an iterative approach. At each observing site and altitude bin, a second-order polynomial was fit to the $\mathrm{CO}_{2}$ time series and then removed, and a mean annual cycle was determined from the thus detrended data by averaging all January data points, all February data points, etc. The mean annual cycle was subtracted from the raw time series, and we again fit a second-order polynomial to the deseasonalized time series. This second polynomial was subtracted from the raw data: we refer to the result as the "detrended time series." This iterative approach is similar to the one described by Cleveland et al. (1983) and used in several carbon cycle studies (e.g., Conway et al. 1994; Matsueda et al. 2002).

For comparing seasonal cycles between CESM data and observations, we computed the mean annual cycle, as described above, from a multiyear, detrended time series. For CESM and NOAA GMD flask data, we determined the mean annual cycle for 1995-2005; for TCCON and NOAA aircraft data, we used the available data and assumed that trends in the mean annual cycle after 2005 were small. To analyze trends in the seasonal cycle shape and amplitude, we first computed an "interannual" time series by removing the mean annual cycle from the detrended time series and smoothing the resulting time series with a 15 -month boxcar filter. This interannual time series was subtracted from the deseasonalized time series to yield high-frequency residuals, and slopes were fitted through all January residuals, all February residuals, etc., to determine the trend for each month (ppm yr ${ }^{-1}$ ) (cf. Randerson et al. 1999).
When analyzing interannual variability (IAV), we used a 2-10-yr bandpass filter to remove seasonal variations at high frequency and the secular increase in $\mathrm{CO}_{2}$ at low frequency. The first and last five years of the combined historical and RCP time series (1850-2100) were removed to avoid edge effects due to the implementation of the bandpass filter. Then we calculated the standard deviation within 30-yr blocks to estimate IAV. Although there were some quantitative differences in the IAV depending on filter cutoffs, the temporal and spatial patterns in IAV were insensitive to the choice of cutoff.

To quantify north-south gradients, we subtracted the southernmost deseasonalized $\mathrm{CO}_{2}$ mole fraction observation available to recenter the CESM output and the observations. This was done because the background $\mathrm{CO}_{2}$ in the model was higher than in observations. For surface data, we subtracted the deseasonalized $\mathrm{CO}_{2}$ mole fraction at SPO. For column data, we subtracted the deseasonalized column mole fraction at Lauder, New Zealand. For HIPPO aircraft profiles, we used the mole fraction at the southernmost surface bin (either $60^{\circ}-90^{\circ} \mathrm{S}$ or $40^{\circ}-$ $60^{\circ} \mathrm{S}$, depending on the campaign) to recenter the data for each northbound or southbound leg.

The amplitude of the mean annual cycle was determined by subtracting the minimum monthly mean $\mathrm{CO}_{2}$ mole fraction from the maximum $\mathrm{CO}_{2}$ mole fraction from the mean annual cycle. Because we determine the amplitude for both the model and observations from monthly means, damping of the seasonal amplitude due to monthly averaging is common to both data types. The trend in the mean annual cycle was likewise calculated from the month of maximum and minimum $\mathrm{CO}_{2}$ mole fraction, similar to the methodology in Randerson et al. (1997), as

$$
T_{\text {amp }}=100 \% \times \frac{b_{\text {max }}-b_{\min }}{C_{\text {max }}-C_{\text {min }}} .
$$

Here $b_{\max }$ and $b_{\min }$ are the slopes of the trends for the months of maximum and minimum $\mathrm{CO}_{2}$ mole fraction, 
TABLE 2. TCCON observatories used for evaluation of CESM. Sites with a mean annual cycle amplitude listed in the table have collected data over at least one complete annual cycle.

\begin{tabular}{|c|c|c|c|c|c|}
\hline \multirow[b]{2}{*}{ Site } & \multirow[b]{2}{*}{ Lat $\left({ }^{\circ} \mathrm{N}\right)$} & \multirow[b]{2}{*}{ Lon $\left({ }^{\circ} \mathrm{E}\right)$} & \multicolumn{2}{|c|}{ Mean annual cycle (ppm) } & \multirow[b]{2}{*}{ Mean annual cycle difference (\%) } \\
\hline & & & TCCON & CESM & \\
\hline Eureka & 80.1 & -86.4 & & 5.8 & \\
\hline Sodankyla & 67.4 & 26.6 & & 5.7 & \\
\hline Bialystok & 53.2 & 23.0 & 7.7 & 4.8 & -38 \\
\hline Bremen & 53.1 & 8.9 & 9.4 & 4.6 & -51 \\
\hline Orleans & 48.0 & 2.1 & & 3.8 & \\
\hline Park Falls & 45.9 & -90.3 & 8.8 & 3.7 & -58 \\
\hline Lamont & 36.6 & -97.5 & 6.3 & 2.5 & -60 \\
\hline Pasadena & 34.1 & 118.1 & 5.9 & 2.3 & -61 \\
\hline Darwin & -12.4 & 130.9 & 1.6 & 0.9 & -43 \\
\hline Wollongong & -34.4 & 150.9 & 1.5 & 0.8 & -47 \\
\hline Lauder & -45.0 & 169.7 & 0.8 & 0.6 & -25 \\
\hline
\end{tabular}

and $C_{\max }$ and $C_{\min }$ are the mean mole fractions for those months. The month of maximum and minimum concentration were not allowed to vary within the decadal periods for which we computed trends in the amplitude.

We diagnosed the phasing of the seasonal cycle using four markers: the seasonal maximum and minimum and the zero crossings between the maximum and the minimum. In the Northern Hemisphere, the first zero crossing occurs in the spring when atmospheric $\mathrm{CO}_{2}$ levels first fall below the annual mean value. The second zero crossing occurs in the fall when atmospheric $\mathrm{CO}_{2}$ increases above its annual mean value after drawdown during the growing season. We determined the day of the year for these four markers by fitting a cubic spline with 1-day time resolution through the mean annual cycle composed of monthly mean data.

\section{Comparison against contemporary observations}

a. Atmospheric growth rate

The multidecadal growth rate of atmospheric $\mathrm{CO}_{2}$ in CESM exceeded observations at Mauna Loa during the latter half of the twentieth century (Fig. 2). By 1958, the start of the instrumental record, $\mathrm{CESM} \mathrm{CO} \mathrm{CO}_{2}$ was high by $4 \mathrm{ppm}$ in the annual mean ( $320 \mathrm{ppm}$ compared to $316 \mathrm{ppm}$ in the observations). This difference increased with time such that, by the end of the historical CESM simulation in 2005, the difference was $20 \mathrm{ppm}$. By integrating the accumulated mass of $\mathrm{CO}_{2}$ for the period from 1958 to 2005 , we determined that the airborne fraction of anthropogenic $\mathrm{CO}_{2}$ contributed from fossil fuel emissions and land use change was about $55 \%$ in CESM compared to $45 \%$ for the observations during this period (Le Quéré et al. 2009), indicating that the combined net

TABLE 3. Aircraft sites with bimonthly or monthly sampling.

\begin{tabular}{|c|c|c|c|c|}
\hline Site & Acronym & Lat $\left({ }^{\circ} \mathrm{N}\right)$ & Lon $\left({ }^{\circ} \mathrm{E}\right)$ & Period \\
\hline Poker Flats, Alaska & PFA & 65.1 & -147.3 & 1999-2012 \\
\hline East Trout Lake, Saskatchewan & ETL & 54.3 & -105.0 & 2005-12 \\
\hline Estevan Point, British Columbia & ESP & 49.4 & -126.5 & $2002-12$ \\
\hline Dahlen, North Dakota & DND & 47.5 & -99.2 & $2004-12$ \\
\hline Park Falls, Wisconsin & LEF & 45.9 & -90.3 & 1998-2012 \\
\hline Fairchild, Wisconsin & FWI & 44.7 & -91.0 & 2004-05 \\
\hline Worcester, Massachusetts & NHA & 42.9 & -70.6 & $2003-12$ \\
\hline Harvard Forest, Massachusetts & HFM & 42.5 & -72.2 & 1999-2007 \\
\hline West Branch, Iowa & WBI & 41.7 & -91.4 & 2004-12 \\
\hline Trinidad Head, California & THD & 41.1 & -124.2 & $2003-12$ \\
\hline Briggsdale, Colorado & CAR & 40.4 & -104.3 & 1992-2012 \\
\hline Beaver Crossing, Nebraska & BNE & 40.8 & -97.2 & 2004-11 \\
\hline Bondville, Illinois & AAO & 40.1 & -88.4 & 2006-09 \\
\hline Homer, Illinois & HIL & 40.1 & -87.9 & 2004-12 \\
\hline Cape May, New Jersey & CMA & 38.8 & -74.3 & $2005-12$ \\
\hline Lamont, Oklahoma & SGP & 36.8 & -97.8 & 1998-2012 \\
\hline Charleston, South Carolina & SCA & 32.8 & -79.6 & 2003-12 \\
\hline Sinton, Texas & TGC & 27.7 & -96.9 & $2003-12$ \\
\hline Molokai Island, Hawaii & HAA & 21.2 & -158.9 & 1999-2008 \\
\hline
\end{tabular}




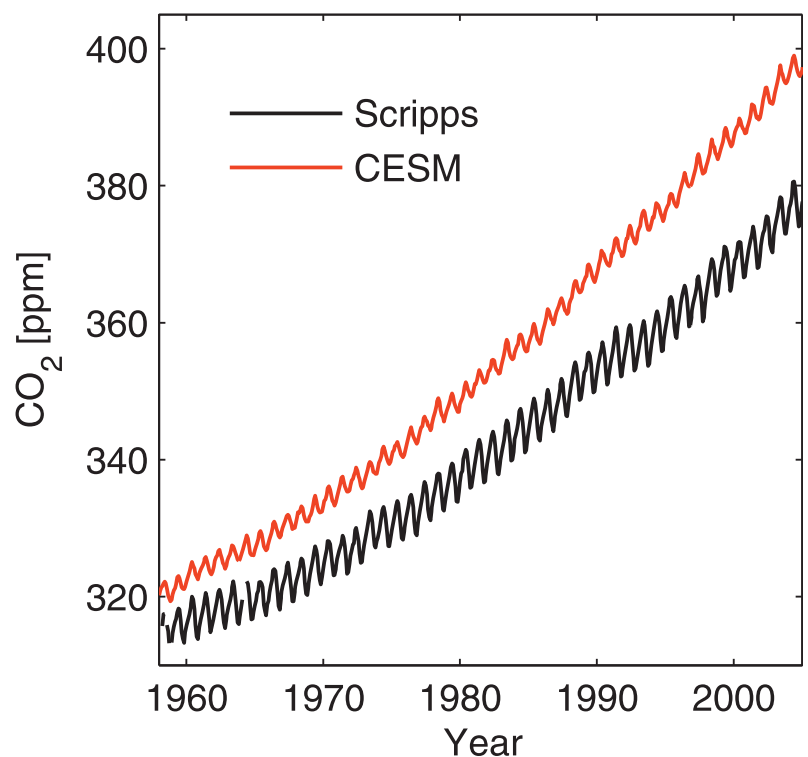

FIG. 2. Observed atmospheric $\mathrm{CO}_{2}$ at Mauna Loa (black) compared to $\mathrm{CO}_{2}$ in CESM sampled at Mauna Loa (red). The growth rate is higher in CESM than observed; the annual mean difference of $4 \mathrm{ppm}$ in 1958 grows to $20 \mathrm{ppm}$ by 2005 . The observations shown are from the SIO carbon program (Keeling et al. 2001).

uptake of $\mathrm{CO}_{2}$ by the land biosphere and oceans was too weak in the model. P. J. Lawrence et al. (2012) and Lindsay et al. (2012, manuscript submitted to J. Climate) show that land use change fluxes were in good agreement with the Global Carbon Project estimates for the period from 1970 to 1999 (Canadell et al. 2007). The residual land sink in CESM for this same period, however, was only $1.3 \mathrm{Pg} \mathrm{C} \mathrm{yr}^{-1}$, while the observationally based estimate reported by the GCP was $2.0 \pm 0.7 \mathrm{Pg} \mathrm{C} \mathrm{yr}^{-1}$. (We define the residual land sink here as the flux component that, when added to the net land use change flux, yields the net land flux.) The net air-to-sea flux in CESM also was slightly small $(-1.9$ versus $-2.0 \pm 0.4$ $\left.\mathrm{Pg} \mathrm{C} \mathrm{yr}^{-1}\right)$. However, it is worth noting that the net ocean carbon sink is sensitive to the partial pressure of atmospheric $\mathrm{CO}_{2}$, which was too high in CESM as a consequence of the cumulative impacts of reduced ocean and land carbon uptake. A comparison of the CESM ocean anthropogenic carbon inventory against observations from Sabine et al. (2004) and Khatiwala et al. (2009) provided evidence that cumulative ocean carbon storage was too weak in the model, partly in response to inadequate ocean vertical exchange in the Southern Ocean (Long et al. 2013; F. Hoffman et al. 2013, unpublished manuscript). Weak ventilation of Southern Ocean waters and weak anthropogenic $\mathrm{CO}_{2}$ uptake was a problem in the CCSM 3.1 model as well (Thornton et al. 2009; Wang et al. 2012) and has been observed in other CMIP3 models (Sarmiento et al. 2000).

\section{b. Seasonal amplitude and phasing}

The Mauna Loa time series also indicates that CESM underestimated the amplitude of the mean annual cycle in the Northern Hemisphere (Fig. 2). A more comprehensive comparison using GMD surface flask observations between 1995 and 2005 indicated that the mean annual cycle was underestimated by $25 \%-40 \%$ in different latitude zones in the Northern Hemisphere (Fig. 3, Table 4). There was substantial site-by-site variation in the agreement of the observed and simulated amplitude and phase.

In the Northern Hemisphere, the onset of the growing season in CESM was too early. Both the maximum and first zero crossing (i.e., when $\mathrm{CO}_{2}$ falls below the annual mean value at a given location) occurred too early (Fig. 4). The first zero crossing was early by almost one month throughout the Northern Hemisphere extratropics, while the timing of the maximum was generally too early but varied with latitude. The model did capture the timing of the seasonal minimum in the Northern Hemisphere.

CESM overestimated the mean annual cycle at the surface in the Southern Hemisphere (Fig. 3, Table 4). The mean amplitudes were between $80 \%$ and $150 \%$ of those determined from flask observations. It is worth noting that the absolute disagreement in amplitude was smaller in the Southern Hemisphere than in the Northern Hemisphere and that the seasonality of Southern Hemisphere $\mathrm{CO}_{2}$ is influenced by Northern Hemisphere terrestrial fluxes (Randerson et al. 1997). In the Southern Hemisphere, the modeled maximum and minimum at surface sites lagged the observations in the tropics and subtropics but were in general agreement south of $40^{\circ} \mathrm{S}$ (Fig. 4). We repeated this analysis using CESM output at NOAA sampling sites, but at $1 \mathrm{~km}$ above the surface (generally within the third model layer) rather than at the surface, to determine whether the biases were caused by rectifier effects in the boundary layer and found similar biases in the mean annual cycle.

The amplitude of the total-column mean annual cycle was also underestimated in CESM (Figs. 5a-d). In the Northern Hemisphere midlatitudes, the seasonal cycle in the column was smaller than observations by $40 \%-60 \%$ (Table 2) and, like the surface data, the seasonal minimum was phase shifted early. Because the seasonal amplitude of column measurements is representative of hemisphericscale fluxes (Keppel-Aleks et al. 2011), we expected the amplitude at different sites to be coherent and for the total underestimation to reflect the amount by which integrated Northern Hemisphere net ecosystem exchange was underestimated by CLM (Keppel-Aleks et al. 2012). These results indicated that the Northern Hemisphere growing season net flux was too small by around $50 \%$ in 


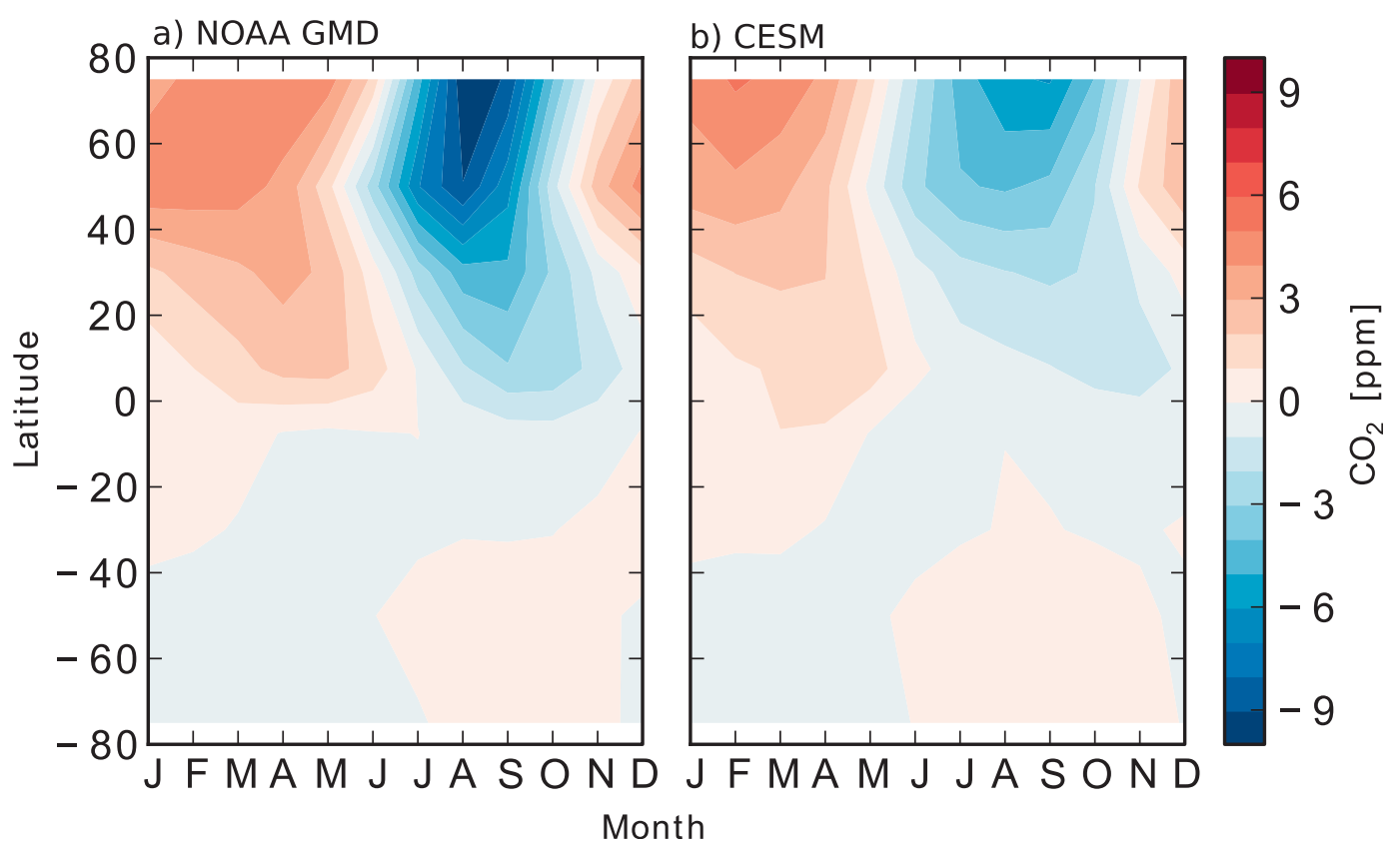

FIG. 3. Hovmöller diagram showing surface $\mathrm{CO}_{2}$ concentrations as a function of latitude and month of year for (a) NOAA GMD observations and (b) CESM sampled at the same locations. The mean annual cycles for each surface station from 1995 to 2005 have been binned into eight north-south regions (defined in Table 1), and the annual mean has been subtracted in each latitude band.

CESM and may be related to the underestimation of soil carbon stocks, as discussed in section 5. Low biases in the column-mean annual cycle persisted in the tropics and in Southern Hemisphere midlatitudes, with CESM underestimating the observations by $30 \%$ and $40 \%$, respectively (Figs. 5e-g).

\section{c. North-south gradients}

The contemporary north-south gradient is determined primarily by the fossil component of $\mathrm{CO}_{2}$ and annualmean land and ocean carbon sinks (Tans et al. 1990). In 1850, the north-south gradient in CESM was nearly flat; the mean contrast between Mauna Loa and the South Pole for $1850-60$ was $0.05 \pm 0.06 \mathrm{ppm}$ standard error (Fig. 6a). The prominent peak in the tropics in the model zonal mean was due to the diurnal covariance of net ecosystem exchange and vertical mixing; at nighttime vertical mixing is suppressed and $\mathrm{CO}_{2}$ from heterotrophic respiration is trapped within the boundary layer (e.g., Fan et al. 1990; Denning et al. 1995). As a result, the mole fractions in the atmospheric boundary layer above tropical ecosystems were large in the annual mean. If only daytime $\mathrm{CO}_{2}$ data were averaged, then the peak in tropical latitudes was not observed (Fan et al. 1990). Likewise, the tropical peak was not observed in the zonal mean for the $\mathrm{CO}_{2}$ total column since this quantity is mostly insensitive to the vertical distribution of $\mathrm{CO}_{2}$.
There was only a gradual change in the north-south gradient between 1850 and the beginning of the atmospheric observational record in the 1950s. During 1950-60, the Mauna Loa-South Pole contrast was $1.2 \pm$ $0.1 \mathrm{ppm}$ (Fig. 6a). The growth of the gradient accelerated between 1950 and 2000 such that between 2000 and 2005, the $\mathrm{CO}_{2}$ contrast between Mauna Loa and South Pole was $3.1 \pm 0.1 \mathrm{ppm}$ (standard error) in CESM, in general agreement with the observed contrast of $2.9 \pm$ $0.1 \mathrm{ppm}$. This growth in the north-south gradient over

TABLE 4. Mean surface seasonal cycle amplitudes in NOAA GMD flask data and CESM for eight north-south bins.

\begin{tabular}{cccc}
\hline \hline Region & $\begin{array}{c}\text { GMD amplitude* } \\
(\mathrm{ppm})\end{array}$ & $\begin{array}{c}\text { CESM amplitude** } \\
(\mathrm{ppm})\end{array}$ & $\begin{array}{c}\text { Difference } \\
(\%)\end{array}$ \\
\hline $60^{\circ}-90^{\circ} \mathrm{N}$ & $14.7 \pm 1.4$ & $11.3 \pm 2.6$ & -23 \\
$40^{\circ}-60^{\circ} \mathrm{N}$ & $14.0 \pm 2.9$ & $8.2 \pm 3.2$ & -41 \\
$15^{\circ}-40^{\circ} \mathrm{N}$ & $9.4 \pm 1.9$ & $5.5 \pm 1.6$ & -41 \\
$0^{\circ}-15^{\circ} \mathrm{N}$ & $5.1 \pm 2.0$ & $3.2 \pm 0.2$ & -37 \\
$0^{\circ}-15^{\circ} \mathrm{S}$ & $1.8 \pm 0.7$ & $2.2 \pm 0.8$ & 22 \\
$15^{\circ}-40^{\circ} \mathrm{S}$ & $1.1 \pm 0.3$ & $0.9 \pm 0.4$ & -18 \\
$40^{\circ}-60^{\circ} \mathrm{S}$ & $1.2 \pm 0.3$ & $1.8 \pm 0.4$ & 50 \\
$60^{\circ}-90^{\circ} \mathrm{S}$ & $1.3 \pm 0.2$ & $1.9 \pm 0.7$ & 46 \\
\hline
\end{tabular}

* Average mean annual cycle amplitude for GMD flask sites located within the latitude band.

** Average mean annual cycle sampled at the same GMD flask sites within CESM. 


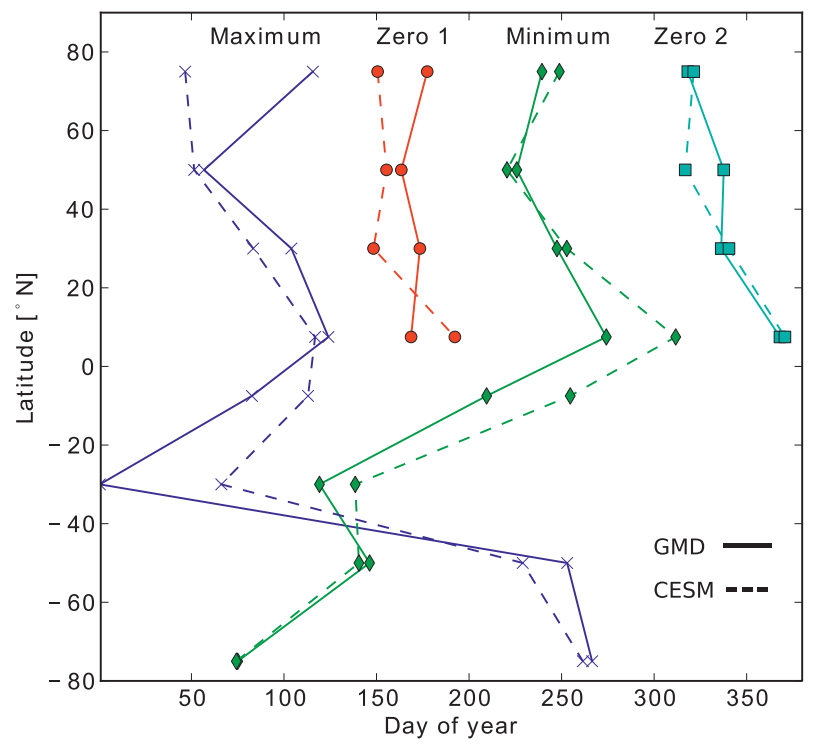

FIG. 4. Phasing of the seasonal cycle in atmospheric $\mathrm{CO}_{2}$ at NOAA GMD flask sites. Solid lines represent observations and dashed lines represent CESM data. In the Northern Hemisphere, the annual maximum mole fraction (blue curves) occurs too early, particularly in the zone from $60^{\circ}$ to $90^{\circ} \mathrm{N}$. The first zero crossing (i.e., when $\mathrm{CO}_{2}$ transitions from above to below the annual mean value) occurs too early by 1 month throughout the Northern Hemisphere extratropics and midlatitudes (red). The annual minimum (green) and second zero crossing (cyan) are better simulated. In the tropics, the summer drawdown in CESM lags the observations. In the Southern Hemisphere, the phasing of the seasonal cycle reverses in the midlatitudes, with the annual maximum occurring after the annual minimum. Zero crossings in the Southern Hemisphere are not plotted because they are not clearly defined.

the historical simulations was due almost entirely to the fact that most fossil fuel emissions occurred in the Northern Hemisphere, therefore driving a large pole-topole gradient (Fig. 6b). The ocean and land contributions to the mean north-south gradient in the model were relatively small and changed by only a small amount between 1850 and 2000 (Figs. 6c,d).

As atmospheric $\mathrm{CO}_{2}$ monitoring began in 1958 at only a few locations and more extensive monitoring began in both hemispheres only in the mid-1970s, we could not directly evaluate long-term changes in the north-south gradient within the model. Previous studies (e.g., Heimann and Keeling 1986; Conway and Tans 1999) have extrapolated the contrast between Mauna Loa and the South Pole to zero emissions to investigate natural $\mathrm{CO}_{2}$ processes that may have existed before the perturbation from fossil fuel $\mathrm{CO}_{2}$. Although interpretation of this approach can be challenging, it was instructive to analyze the Mauna Loa-South Pole contrast for CESM as it revealed a significantly different pattern than the observations (Fig. 7). A linear regression through the NOAA
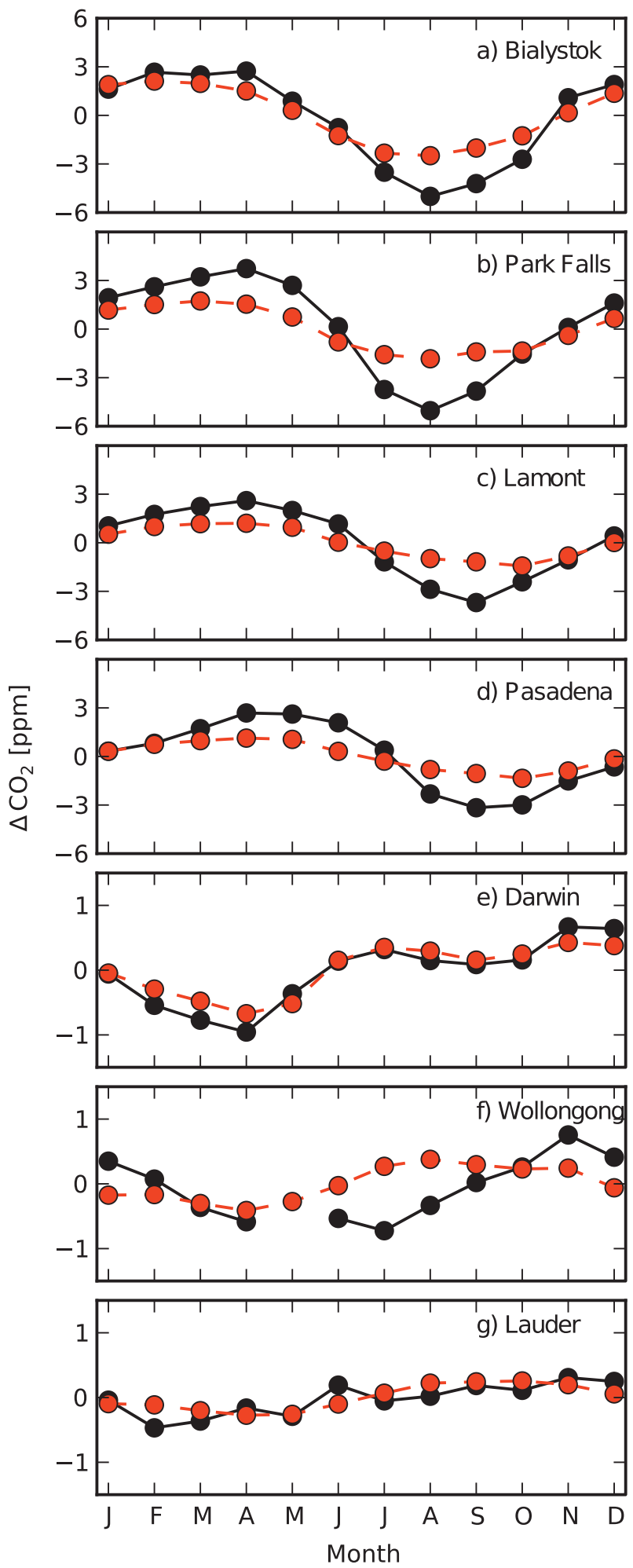

FIG. 5. Mean annual cycle in column $\mathrm{CO}_{2}$ sampled at seven TCCON sites with a full year of data compared to CESM sampled at the same locations: (a) Bialystok, (b) Park Falls, (c) Lamont, (d) Pasadena, (e) Darwin, (f) Wollongong, and (g) Lauder. The $y$ axis scale has been changed for the Southern Hemisphere sites [panels (e)-(g)]. 


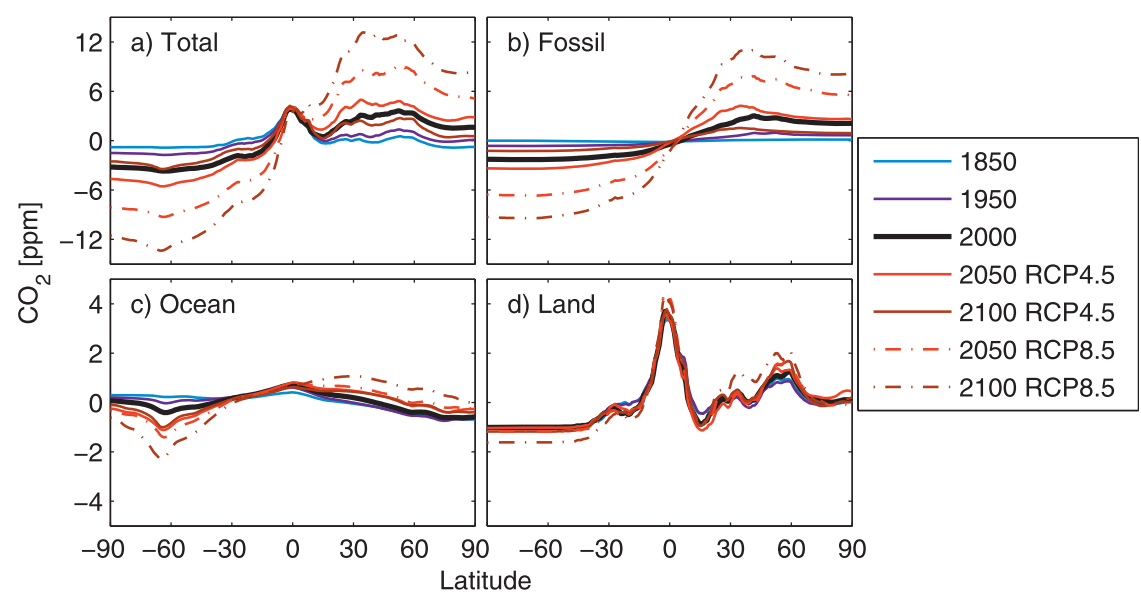

FIG. 6. Evolution of the meridional distribution of surface $\mathrm{CO}_{2}$ in $\mathrm{CESM}$. The annual mean model output shown here was averaged for each $0.9^{\circ}$-wide latitude band. The (a) model total can be separated into (b) fossil fuel, (c) ocean flux, and (d) land flux components because these tracers were carried separately in the simulations. The high $\mathrm{CO}_{2}$ in the tropics in (a) and (d) is due to ecosystem respiration by the terrestrial biosphere being mixed into a shallow nighttime boundary layer over land. Note the change of $y$ axis scale in (c) and (d) relative to (a) and (b). For the total and each component, the global annual mean atmospheric mole fraction is removed to enable more direct comparisons of the changing north-south gradient over time.

GMD data had a slope of $0.56 \pm 0.08 \mathrm{ppm}\left(\mathrm{Pg} \mathrm{C} \mathrm{yr}^{-1}\right)^{-1}$ and an intercept of $-1.2 \pm 0.4 \mathrm{ppm}$. A simple interpretation might suggest that, in the absence of fossil fluxes, the Northern Hemisphere would have lower $\mathrm{CO}_{2}$ than the Southern Hemisphere due to a natural Southern Hemisphere source. The CESM results give a slope of $0.39 \pm 0.04 \mathrm{ppm}\left(\mathrm{Pg} \mathrm{C} \mathrm{yr}^{-1}\right)^{-1}$ and a positive intercept of $0.3 \pm 0.2 \mathrm{ppm}$ for the observational period from 1958 and 2005. For the full CESM record (1850-2005), the slope was similar $0.42 \pm 0.02 \mathrm{ppm}\left(\mathrm{Pg} \mathrm{C} \mathrm{yr}^{-1}\right)^{-1}$, and the actual difference prior to fossil fuel emissions was $0.2 \pm 0.1 \mathrm{ppm}$. The positive intercept for the recent data in CESM may reflect a lack of Southern Ocean overturning that would limit ventilation of $\mathrm{CO}_{2}$-rich waters in the far south (Long et al. 2013). We hypothesize that models with weak Southern Ocean outgassing also may have lower rates of twentieth-century anthropogenic carbon uptake owing to the role of Southern Ocean overturning on both time scales (e.g., Lovenduski et al. 2008; Khatiwala et al. 2009; Lovenduski and Ito 2009). Thus, the model biases in $\mathrm{CO}_{2}$ growth (Fig. 2) and emissions versus interhemispheric gradient (Fig. 7) may be related.

As with many of the metrics presented in this paper, the observed $\mathrm{CO}_{2}$ gradients often are a result of multiple factors and thus are only a partial constraint on a single process. Errors in the magnitude, spatial distribution, and timing of land use change emissions, for example, could also affect the trend in the Mauna Loa-South Pole contrast. The preindustrial north-south gradient inferred from the observations is also probably influenced by land-ocean lateral carbon fluxes (e.g., Finzi et al. 2011) that are accompanied by a more uniform breakdown within the ocean of more refractory terrestrial carbon, although inverse modeling results show that these fluxes are small (Jacobson et al. 2007), and by rates of interhemispheric atmospheric mixing. Diagnosing these contributions would require additional simulations and are beyond the scope of this study.

The north-south $\mathrm{CO}_{2}$ gradient varies considerably as a function of season (Fig. 8). It is highest in late winter when fossil fuels and ecosystem respiration fluxes are the primary land surface fluxes and reverses during summer when photosynthetic drawdown exceeds ecosystem respiration and fossil emissions (Fig. 3). The meridional gradient at the surface in CESM did reasonably well at representing the annual mean of the observations (Fig. 8a). During February, north of $40^{\circ}$, the model was higher than GMD sites by $0.6 \pm 0.6 \mathrm{ppm}$ (standard error across 14 sites, Fig. 8b), while in the summer, the model was $6.0 \pm$ $0.6 \mathrm{ppm}$ (standard error across 14 sites) higher than the Global Monitoring Division observations north of $40^{\circ}$ (Fig. 8c). The shallow Northern Hemisphere growing season gradient was consistent with underestimation of Northern Hemisphere $\mathrm{CO}_{2}$ uptake during summer and a correspondingly weak mean annual cycle (Fig. 3). Although the modeled surface $\mathrm{CO}_{2}$ mole fraction was high in both winter and summer, the model agreed in the annual mean north of $40^{\circ} \mathrm{N}$ because CESM had excessively large drawdown in spring that lowered the annual mean value. 


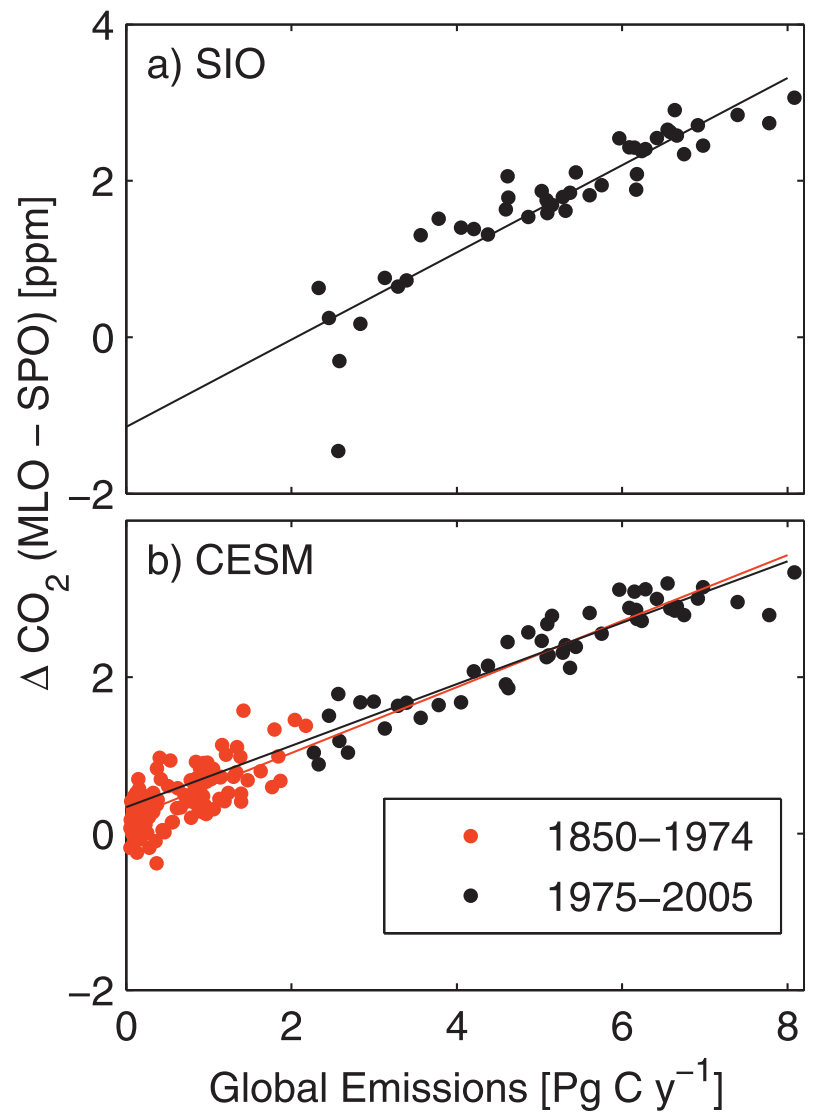

FIG. 7. Interhemispheric difference in atmospheric $\mathrm{CO}_{2}$ plotted as a function of fossil fuel emissions [for observations from Boden et al. (2009)]. The contrast between Mauna Loa and South Pole $\mathrm{CO}_{2}$ in (a) the SIO observations and (b) CESM is plotted. For CESM, black circles represent model output coincident with the data record (1958-2005) and the red circles represent the model output prior to $\mathrm{CO}_{2}$ observations (1850-1957). The slope and intercept for the data were $0.56 \mathrm{ppm}\left(\mathrm{Pg} \mathrm{C} \mathrm{yr}^{-1}\right)^{-1}$ and $-1.15 \mathrm{ppm}$. CESM had a smaller slope of $0.39 \mathrm{ppm}\left(\mathrm{Pg} \mathrm{C} \mathrm{yr}^{-1}\right)^{-1}$ for the contemporary record and a positive intercept of $0.3 \mathrm{ppm}$. Using all years from the model simulation changed the intercept to $0.2 \mathrm{ppm}$, which reduced but did not eliminate the apparent model bias.

The north-south $\mathrm{CO}_{2}$ gradient was likewise underestimated in the column in CESM during Northern Hemisphere summer (Fig. 9). In the annual mean (Fig. 9a), the model and data generally agreed, while in February the CESM was slightly lower than observations in the Northern Hemisphere. In August the CESM was higher than observations throughout the Northern Hemisphere, with an increasing positive bias in northern regions. The two high-latitude sites, Sodankyla and Eureka, operated only during the summer when simulated column $\mathrm{CO}_{2}$ was 4 ppm higher than the observations.

A comparison of CESM with HIPPO transects revealed how north-south gradients vary with altitude across seasons. For the surface layer, the north-south gradient was
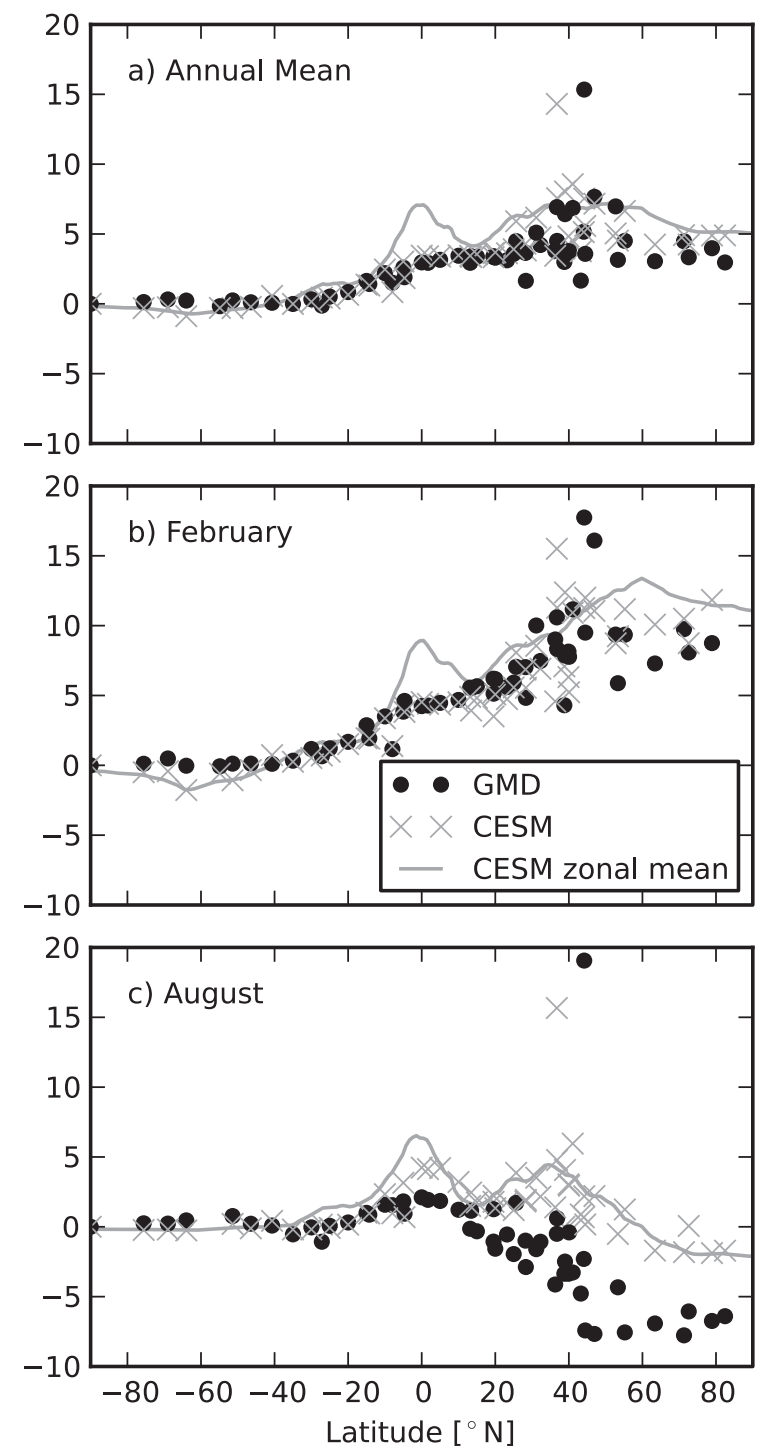

FIG. 8. Meridional distribution of CESM surface $\mathrm{CO}_{2}$ relative to observations at NOAA GMD flask sites plotted for the (a) annual mean, (b) February, and (c) August. In all panels, the thin gray line represents the zonal mean surface $\mathrm{CO}_{2}$ concentration in the model, while the gray crosses represent CESM sampled at NOAA GMD flask observatories. The black circles represent the observations.

overestimated in the model during January. During March and April (Figs. 10b,c), Northern Hemisphere CESM data were lower than HIPPO data, perhaps due to early spring drawdown in CESM. Although initial drawdown was evident along HIPPO flight tracks in June, in CESM this was significantly more advanced for all latitudes and altitudes in the tropics and Northern Hemisphere (Fig. 10d). From June to July (Fig. 10e) the HIPPO data indicated carbon uptake increased in the northern part of the Northern Hemisphere, whereas the simulations showed no additional drawdown. The weak summer 


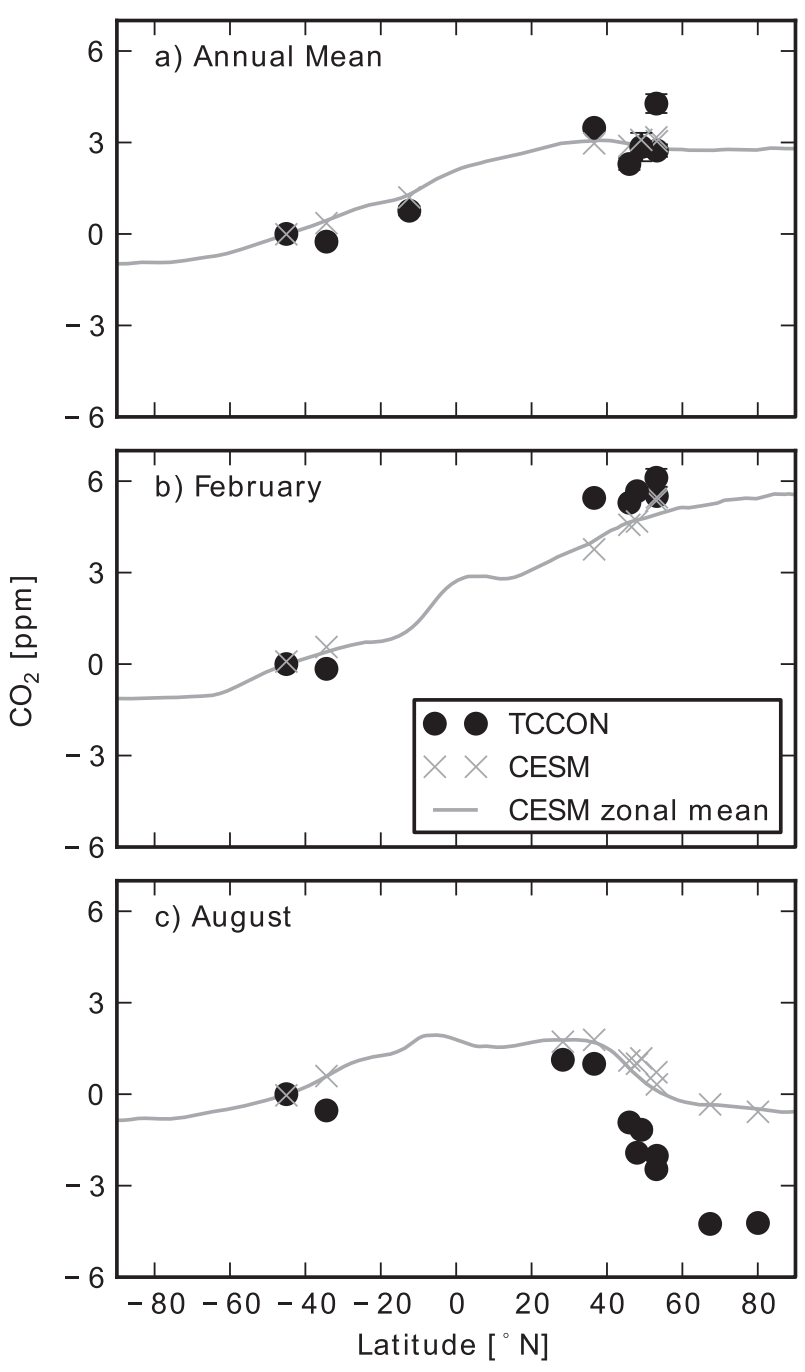

FIG. 9. Meridional distribution of column $\mathrm{CO}_{2}$ in CESM compared to observations from TCCON sites plotted for the (a) annual mean, (b) February, and (c) August. In all panels, the thin gray line represents the zonal mean column $\mathrm{CO}_{2}$ concentration in the model, while the gray crosses represent CESM sampled at TCCON observatories. The black circles represent the observations.

drawdown in CESM was most apparent in August and September (Figs. 10f,g). The model showed surface $\mathrm{CO}_{2}$ mole fractions higher by $5 \mathrm{ppm}$ and free tropospheric $\mathrm{CO}_{2}$ mole fractions higher by $2-5 \mathrm{ppm}$. In autumn $\mathrm{CO}_{2}$ was generally too high along HIPPO transects (Figs. 10h,i). The pole-to-pole north-south gradients were smaller aloft than at the surface in both observations and simulations for all months, with the magnitude of the north-south gradient aloft tied to the strength of the gradient at the surface. For all of the comparisons shown in Fig. 10, the CESM estimates were a 5-yr mean sampled along the flight tracks to approximate climatological mean patterns. It is important to note that the
October and November HIPPO data described above were obtained during 2009 during the transition to a strong La Niña, but this likely has a small effect on the model-data mismatch compared to the weak seasonal exchange in CESM.

\section{d. Vertical structure in the model}

The agreement in vertical $\mathrm{CO}_{2}$ stratification between CESM and HIPPO observations varied considerably as a function of season, with summer CESM data generally less vertically stratified than the HIPPO free tropospheric $\mathrm{CO}_{2}$ (Fig. 10). In January (Fig. 10a) CESM CO showed vertical gradients of $4 \mathrm{ppm}$ between the surface and $10 \mathrm{~km}$ in the Northern Hemisphere, roughly similar to those in the observations. Coincident with growing season onset in March and April (Figs. 10b,c), the vertical gradients in CESM decreased such that, during the peak of the growing season, vertical gradients were quite small. During June and July (Figs. 10d,e) both datasets showed small vertical gradients of 1-2 ppm between the surface and $10 \mathrm{~km}$. In August (Fig. 10f) HIPPO data increased by greater than $5 \mathrm{ppm}$ between the surface and $10 \mathrm{~km}$ in regions poleward of $40^{\circ} \mathrm{N}$. In CESM, however, the vertical contrast over this altitude range was only $2 \mathrm{ppm}$. This model-data mismatch persisted into September.

Analysis of the vertical propagation of the annual cycle in NOAA and DOE southern Great Plains (SGP) aircraft data indicated that annual-mean vertical gradients in CESM were broadly consistent with those observed in the Northern Hemisphere (Fig. 11). The mean annual cycle amplitudes in 1-km altitude bins throughout the lower troposphere were normalized to the amplitude of the mean annual cycle below $1 \mathrm{~km}$ in an attempt to account for biases in the magnitude of seasonal surface fluxes in the model (e.g., Yang et al. 2007). Between $20^{\circ}$ and $40^{\circ} \mathrm{N}$ the mean annual cycle amplitude decreased somewhat more rapidly with altitude in CESM than it did in the observations (Fig. 11a), which may suggest weak vertical coupling between the surface layer and the free troposphere (Yang et al. 2007), although the seasonal amplitude aloft also may have been diminished by the propagation of fluxes from northern regions, which are demonstrably too weak in CESM. North of $40^{\circ} \mathrm{N}$ (Figs. $11 \mathrm{~b}, \mathrm{c})$ the rate of decrease in the mean amplitude was similar for CESM and the observations, although the site-to-site behavior was quite heterogeneous.

Consistent with the HIPPO profiles, $\mathrm{CESM} \mathrm{CO}_{2}$ showed more vertical stratification at the GMD and DOE aircraft sites during winter than summer (Fig. 12). The observed summer profiles varied by $6 \mathrm{ppm}$ from the surface to $10 \mathrm{~km}$, but were mostly uniform in CESM, except for a small enhancement in CESM below $1 \mathrm{~km}$. This surface enhancement was not present at all sampling 


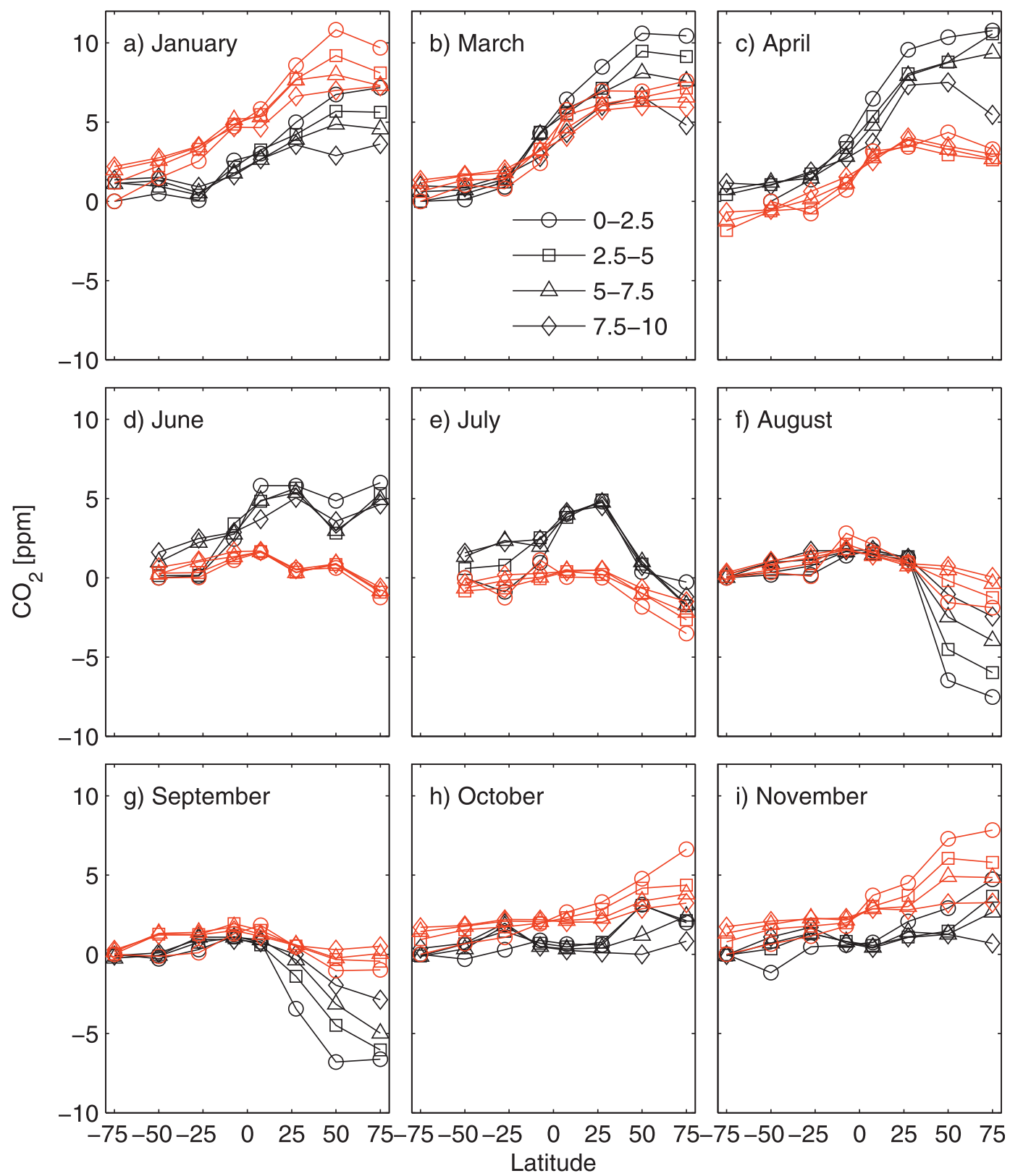

FIG. 10. Free tropospheric $\mathrm{CO}_{2}$ measured during the HIPPO campaigns (black) and sampled in CESM at corresponding locations (red) for the data averaged into eight latitude bands and four altitude bins: the surface to $2.5 \mathrm{~km}$ (circles), 2.5-5.0 km (squares), 5.0-7.5 km (triangles), and 7.5-10.0 km (diamonds). Each panel represents a different northbound or southbound campaign in (a) January 2009 (southbound), (b) March 2010 (southbound), (c) April 2010 (northbound), (d) June 2011 (southbound), (e) July 2011 (northbound), (f) August 2011 (southbound), (g) September 2011 (northbound), (h) October 2009 (southbound), and (i) November 2009 (northbound).

locations and may simply be a consequence of the diurnal rectifier. We were not able to test this because CESM data were not archived at a temporal resolution higher than 1 day for most of the atmosphere (for all atmospheric levels above the surface layer).

The somewhat sluggish rate of atmospheric vertical mixing (suggested by Fig. 11a) may explain why the seasonal cycle amplitudes agreed better at the surface in the Northern Hemisphere (Table 4) than in the column (Table 2). The weak vertical gradients during Northern Hemisphere summer in CESM compared to both HIPPO and NOAA aircraft profiles (Figs. 10,12) may be mostly caused by weak surface fluxes. Similarly, in winter the reasonable agreement between model and observations 


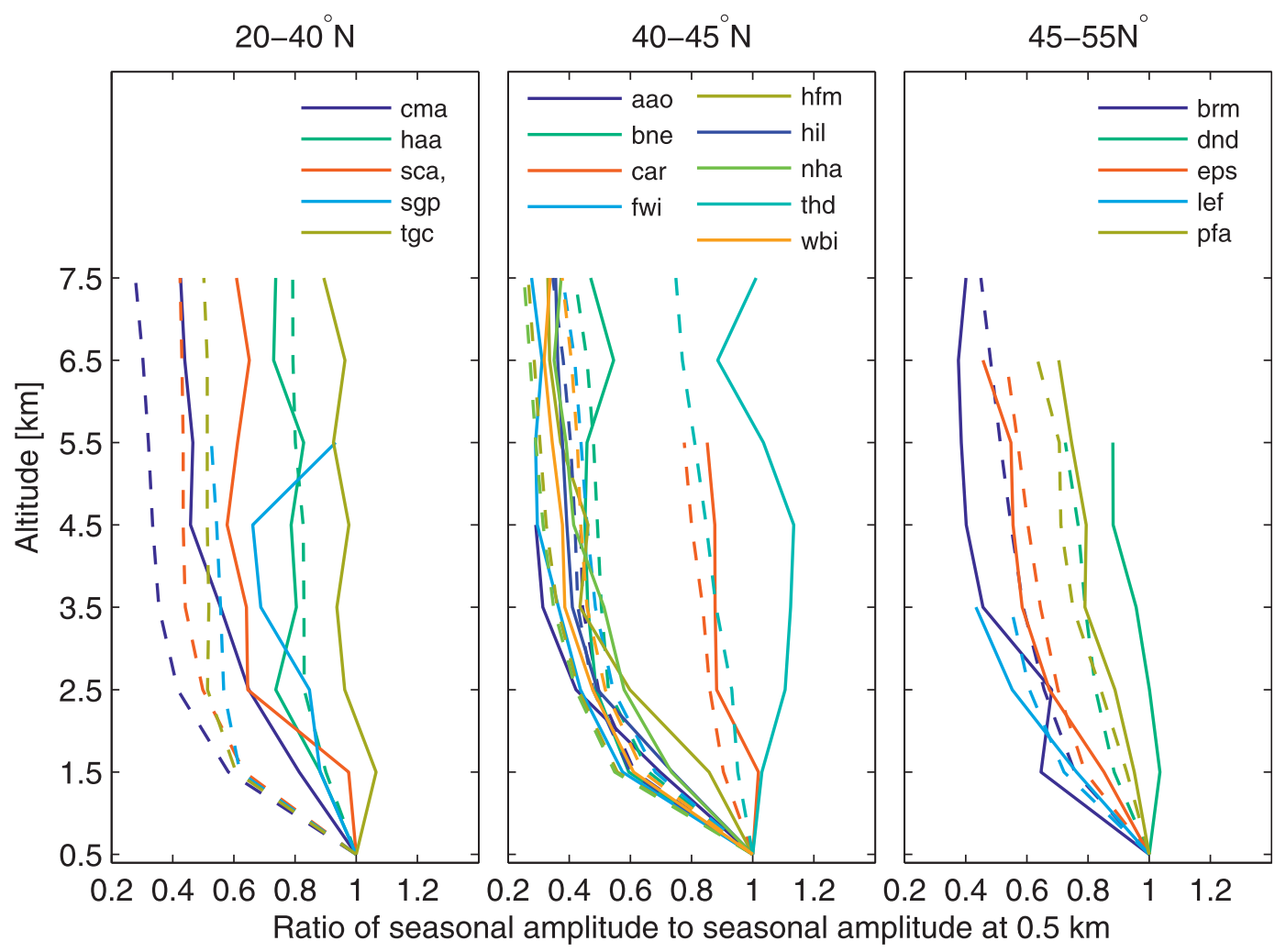

FIG. 11. Ratio of the seasonal cycle amplitude in NOAA GMD and DOE aircraft data at several altitudes to the seasonal cycle amplitude below $1 \mathrm{~km}$ (solid lines): CESM (dashed lines) is sampled at the locations of the aircraft profiles. Shown are binned aircraft data into eight vertical layers of 1-km depth from the surface to $8 \mathrm{~km}$ and interpolated $\mathrm{CESM} \mathrm{CO}$ profiles to the bin midpoint. The mean seasonal cycle amplitude in each layer for both the data and the model was calculated. An attempt was made to isolate the role of vertical transport in setting the mean annual cycle at different altitudes by normalizing the mean annual cycle amplitude in each layer by the amplitude for the corresponding data type (observation or model) in the layer centered at $0.5 \mathrm{~km}$, similar to the methodology described by Yang et al. (2007), to account for differences in surface fluxes. The sites are separated by latitude for clarity in plotting.

may result from the combined effects of weak biosphere emissions outside the growing season and weak transport. A more conclusive diagnosis of transport, as discussed in section 5, will require additional simulations with new tracers. We note that, at some locations in the Northern Hemisphere, the surface mole fraction was higher in CESM during winter than in the NOAA and DOE observations (Fig. 8b) or HIPPO observations (Fig. 10a), even though surface fluxes were weaker. Any surface enhancement in CAM (e.g., the increase below $1 \mathrm{~km}$ in Fig. 12) also could have contributed to the mean annual cycle amplitude at the surface being inflated relative to the mean annual cycle aloft. In summary, the largest model discrepancy was a reduced seasonal cycle in the Northern Hemisphere, which manifested as weak north-south and vertical gradients during summer. It was difficult to distinguish between mixing and fluxes, but the comparison to column data suggests that the fluxes were $50 \%$ too weak and the better agreement at surface sites suggests mixing also plays a role in amplifying the surface mean annual cycle.

\section{e. East-west gradients}

We present one example of growing east-west gradients created by increasing fossil fuel $\mathrm{CO}_{2}$ at the NOAA GMD site on the Tae-Ahn peninsula in South Korea, where the air is transported from heavily populated regions in China and industrial centers in South Korea (Turnbull et al. 2011), relative to background stations in the Northern and Southern Hemispheres. These background stations included Mace Head, which samples relatively clean airflow from the Atlantic, Mauna Loa, and Samoa. We detrended each site relative to the South Pole; thus, each site retained the signature of the increasing north-south gradient (Fig. 6). Deseasonalized NOAA GMD data from the early 1990s to 2010 showed that the increase relative to the South Pole on the TaeAhn peninsula since 1992 was faster than the increase at 


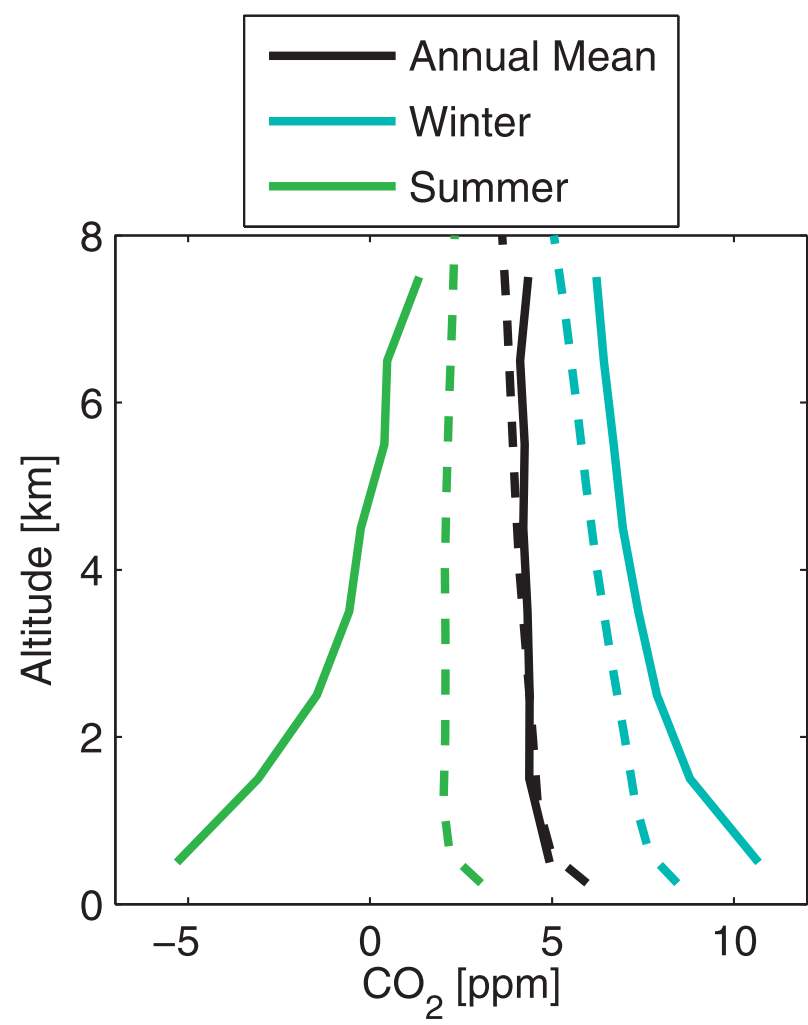

FIG. 12. Vertical profiles in NOAA GMD aircraft data (solid lines) and CESM (dashed lines). We plot annual mean, winter (January-March) and summer (July-September) for sites between $40^{\circ}$ and $60^{\circ} \mathrm{N}$. This figure follows an approach similar to Stephens et al. (2007), with the mole fractions recentered by the deseasonalized surface mole fraction at South Pole.

Mace Head and Mauna Loa by about a factor of 3 (0.17 $\mathrm{ppm} \mathrm{yr}^{-1}$ compared to $0.06 \mathrm{ppm} \mathrm{yr}^{-1}$ ) (Table 5) and that the trends were correlated with Chinese emissions (Fig. 13a).

This pattern across the different stations was consistent with observations that China and Korea emissions increased at a rate that was several fold larger than the hemispheric mean during this interval and that the TaeAhn peninsula site was in close proximity to these source regions (Boden et al. 2009; Turnbull et al. 2011). At all three Northern Hemisphere sites, $\mathrm{CO}_{2}$ increased faster than at Samoa, due at least in part to the fact that the north-south gradient is increasing with time (Fig. 6). CESM output for the same time period revealed a similar trend at Tae-Ahn compared to the observations. The fossil fuel component of $\mathrm{CO}_{2}$ was primarily responsible for the higher increase at the site relative to the other Northern Hemisphere sites, although we did not carry separate tracers for China and Korea (or other countries) to enable further attribution (Table 5). The growth rate trends were slightly smaller at Mace Head and Mauna Loa than in the observations, but the fossil
TABLE 5. Atmospheric $\mathrm{CO}_{2}$ increase relative to the South Pole from 1992 to 2010 .

\begin{tabular}{lccc}
\hline \hline \multicolumn{1}{c}{ Site } & $\begin{array}{c}\text { GMD } \\
\text { trend } \\
\left(\mathrm{ppm} \mathrm{yr}^{-1}\right)\end{array}$ & $\begin{array}{c}\text { CESM } \\
\text { trend } \\
\left(\mathrm{ppm} \mathrm{yr}^{-1}\right)\end{array}$ & $\begin{array}{c}\text { CESM } \\
\text { fossil trend } \\
\left(\mathrm{ppm} \mathrm{yr}^{-1}\right)\end{array}$ \\
\hline Mace Head (MHD) & $0.06 \pm 0.02$ & $0.02 \pm 0.04$ & $0.07 \pm 0.02$ \\
Tae-Ahn & $0.17 \pm 0.06$ & $0.19 \pm 0.09$ & $0.19 \pm 0.06$ \\
$\quad$ Peninsula (TAP) & & & \\
Mauna Loa (MLO) & $0.06 \pm 0.01$ & $0.02 \pm 0.02$ & $0.06 \pm 0.01$ \\
Samoa (SMO) & $0.03 \pm 0.01$ & $-0.04 \pm 0.02$ & $0.01 \pm 0.01$
\end{tabular}

component of the trend was similar in magnitude to the observed total at each site. Given that CESM was able to capture the faster accumulation rate of $\mathrm{CO}_{2}$ at the Tae-Ahn peninsula relative to more remote stations (Table 5) and that this gradient is likely to increase many fold in the future with greater energy consumption in China (Figs. 13b,c), there is potential to use the existing monitoring network to constrain regional increases in fossil emissions over time (National Research Council 2010).

\section{f. Trends in the seasonal cycle}

Analysis of trends in the mean annual cycle of atmospheric $\mathrm{CO}_{2}$ during the contemporary period may reveal how $\mathrm{CO}_{2}$ varies in response to contemporary climatic variations and changes in atmospheric composition (Table 6). Previous studies have noted changes in the seasonality of $\mathrm{CO}_{2}$ (e.g., C. D. Keeling et al. 1996; Randerson et al. 1997; Piao et al. 2008) owing mostly to increased seasonality in land biosphere fluxes. We calculated the trend in the seasonal cycle amplitude using Eq. (1) at 17 NOAA GMD sites that had mostly continuous coverage during 1980-2005 and sampled the model for the corresponding period. The agreement in the calculated trends varied considerably among sites. Both observations and the CESM showed consistent increases of around $0.5 \% \mathrm{yr}^{-1}$ to the mean annual cycle amplitude at two high northern latitude sites, Alert and Barrow. In addition we found that in CESM there were negative trends on the shoulders of the growing season at these sites, suggesting lengthening of the growing season that was not evident in the observed trends. At mid and low latitudes of the Northern Hemisphere between $0^{\circ}$ and $40^{\circ} \mathrm{N}$, the observations generally had smaller positive trends. Within this zone, CESM generally overestimated the observed amplitude increases. Randerson et al. (1997) noted that the role of transport acting on gradients in fossil fuel $\mathrm{CO}_{2}$ plays a significant role in setting the seasonal cycle at stations near the equator in both Northern and Southern Hemispheres. As a result, increases in the north-south gradient from increasing fossil fuel emissions over this $25-\mathrm{yr}$ analysis 

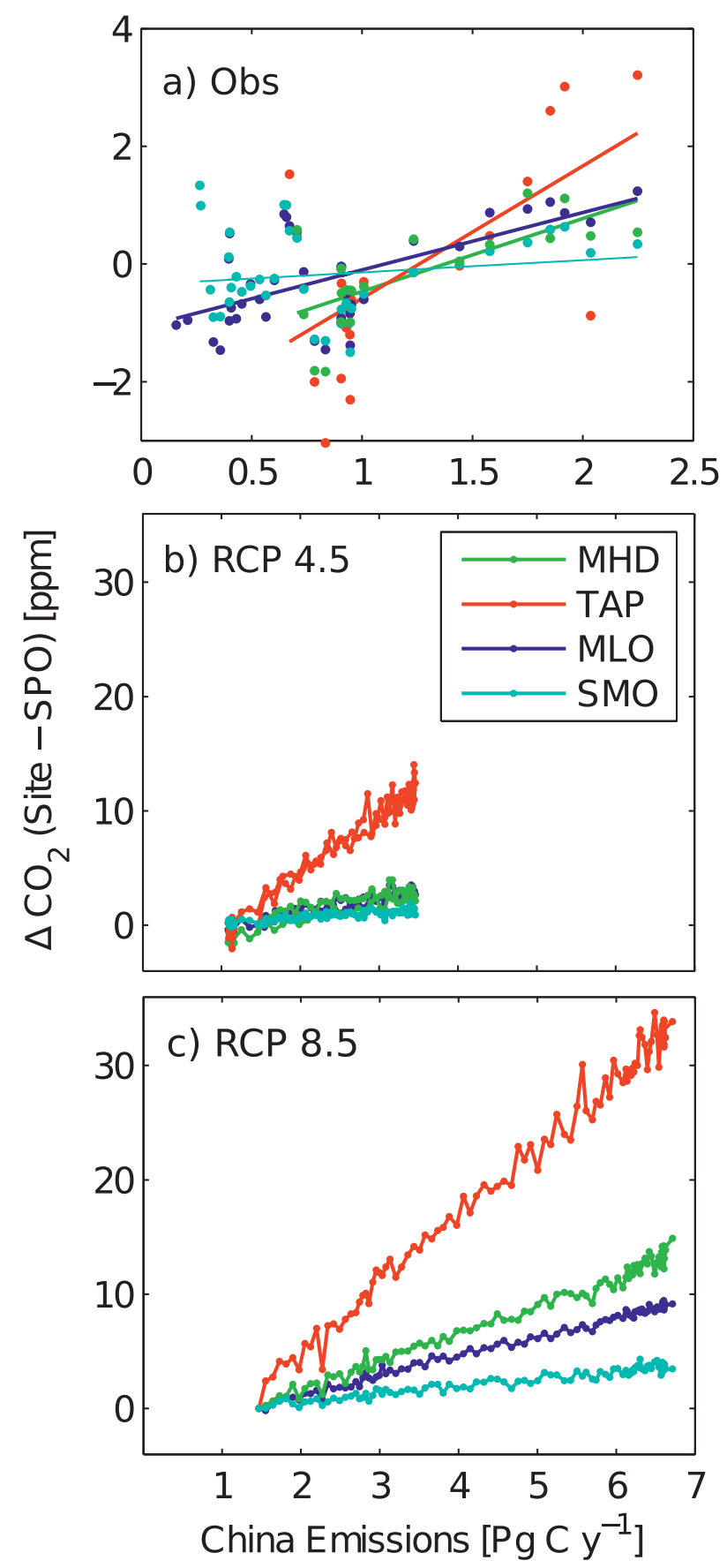

FIG. 13. Growth in $\mathrm{CO}_{2}$ relative to SPO for four Northern Hemisphere sites as a function of Chinese fossil fuel emissions in the (a) contemporary data record (NOAA surface flasks; Conway et al. 1994): all available data from Mace Head, Tae-Ahn peninsula, Mauna Loa, and Samoa: estimates of emissions and CESM in $\mathrm{CO}_{2}$ from the (b) RCP4.5 scenario during 2006-2100 and similarly for the (c) RCP8.5 scenario is plotted. The trend at Tae-Ahn Peninsula, South Korea, is larger than that at other Northern Hemisphere sites due to its proximity to Chinese and South Korean emissions. period likely contributed to some of the average positive trends observed in the NOAA GMD measurements and in CESM.

\section{g. Interannual variability}

Interannual variations in CESM were smaller than those in GMD flask data. Table 6 lists the IAV in the $\mathrm{CO}_{2}$ time series for the same 17 sites discussed above from 1980 to 2005. CESM IAV was approximately $50 \%$ that of observed $\mathrm{CO}_{2}$ IAV during this time period. The interannual variability (IAV) was somewhat larger in the Northern than in the Southern Hemisphere in the data, whereas the two hemispheres had similar IAV in the model.

Interannual variability in $\mathrm{CO}_{2}$ remained relatively constant during the historical simulation (Figs. 14a,b). We took advantage of the fact that land, ocean, and fossil components of atmospheric $\mathrm{CO}_{2}$ were tagged separately in CESM to explore the sources of interannual variability in each latitude band (Fig. 14). In CESM, land $\mathrm{CO}_{2}$ was the primary source of interannual variability from 1850 to 2005, even in the Southern Hemisphere. The IAV in the fossil component of $\mathrm{CO}_{2}$ grew during the twentieth century in all latitude bands, but the increase was largest in the Northern Hemisphere between $15^{\circ}$ and $60^{\circ} \mathrm{N}$ where most fossil fuel $\mathrm{CO}_{2}$ was emitted. The fossil component of $\mathrm{CO}_{2}$ generally showed larger IAV than the ocean component from 1850 to 2005, except in the tropical bands between $15^{\circ} \mathrm{S}$ and $15^{\circ} \mathrm{N}$.

The sum of the IAV for the fossil, land, and ocean components was greater than the IAV for the total $\mathrm{CO}_{2}$, suggesting that variations in one component were compensated by the other components. An asynchronous phasing of land and ocean fluxes to ENSO variability in the model (Lindsay et al. 2012, manuscript submitted to J. Climate) is probably a driver of some of this compensation, which was also noted in Doney et al. (2006). Assuming that the fossil fuel component of the IAV was well captured by CESM for the historical simulations (i.e., source emissions were approximately correct and atmospheric transport was not a large error source on these longer time scales), these results indicated that interannual variability owing to terrestrial biosphere and ocean fluxes, in particular interannual variability in the land biosphere, was too small in CESM given the underestimate of IAV at GMD sites (Fig. 6). The implementation of nitrogen coupling in the $\mathrm{C}-\mathrm{N}$ biogeochemistry model may be partly responsible for reducing the magnitude of net primary production (Thornton et al. 2007) and, thus, the contribution of this gross flux component to net ecosystem exchange variations driven by year-to-year changes in climate. Interannual variability in fires from the model was also lower 
TABLE 6. Amplitude trends in the mean annual cycle and interannual variability (IAV). GMD flask sites were selected that have nearly continuous data coverage from 1980 to 2005 and sampled CESM coincidentally. The amplitude trend is calculated from Eq. (1). Interannual variability is defined as the standard deviation in bandpass-filtered (2-10-yr filter cutoffs) time series.

\begin{tabular}{|c|c|c|c|c|c|c|}
\hline Site & Lat & Period & GMD trend $\left(\% \mathrm{yr}^{-1}\right)$ & CESM trend $\left(\% \mathrm{yr}^{-1}\right)$ & GMD IAV (ppm) & CESM IAV (ppm) \\
\hline Alert & 82.5 & $1985-2005$ & 0.6 & 0.5 & 0.9 & 0.4 \\
\hline Barrow & 71.3 & 1980-2005 & 0.7 & 0.5 & 0.8 & 0.4 \\
\hline Cold Bay & 55.2 & 1980-2005 & 0.2 & 0.7 & 0.9 & 0.4 \\
\hline Shemya & 52.7 & $1985-2005$ & 0.0 & 0.3 & 0.7 & 0.4 \\
\hline Niwot Ridge & 40.1 & 1980-2005 & -0.1 & 2.0 & 0.7 & 0.4 \\
\hline Azores & 38.8 & $1980-2005$ & 0.0 & 0.0 & 0.8 & 0.3 \\
\hline Midway Island & 28.2 & 1985-2005 & 0.1 & 0.7 & 0.8 & 0.4 \\
\hline Key Biscayne & 25.7 & $1985-2005$ & 0.2 & 0.2 & 0.8 & 0.4 \\
\hline Mauna Loa & 19.5 & 1980-2005 & 0.1 & 0.3 & 0.7 & 0.3 \\
\hline Kumukahi & 19.5 & $1980-2005$ & -0.1 & 0.3 & 0.6 & 0.3 \\
\hline Guam & 13.4 & 1980-2005 & -0.1 & 0.2 & 0.8 & 0.3 \\
\hline Seychelles & -4.7 & 1980-2005 & 1.0 & 2.3 & 0.9 & 0.4 \\
\hline Ascension Island & -8.0 & 1980-2005 & 1.1 & -0.5 & 0.6 & 0.4 \\
\hline Christmas Island & -10.5 & 1984-2005 & -0.2 & 0.6 & 0.6 & 0.3 \\
\hline Samoa & -14.3 & $1980-2005$ & 3.3 & 1.8 & 0.6 & 0.3 \\
\hline Palmer Station & -64.9 & 1980-2005 & -0.7 & 1.4 & 0.7 & 0.3 \\
\hline South Pole & -90.0 & 1980-2005 & -1.0 & 1.3 & 0.6 & 0.3 \\
\hline
\end{tabular}

than estimates derived from satellite observations of burned area and active fires (van der Werf et al. 2010; Kloster et al. 2010).

\section{Evolution of $\mathrm{CO}_{2}$ variability in $\mathrm{RCP}$ scenarios}

In the representative concentration pathways RCP4.5 scenario, global emissions increased from $8 \mathrm{Pg} \mathrm{C} \mathrm{yr}^{-1}$ in 2005 to $9.0 \mathrm{Pg} \mathrm{C} \mathrm{yr}^{-1}$ in 2040 before declining to around $4 \mathrm{Pg} \mathrm{C} \mathrm{yr}^{-1}$ in 2088 and leveling off (Fig. 15a), resulting in an atmospheric $\mathrm{CO}_{2}$ mole fraction of $610 \mathrm{ppm}$ at Mauna Loa in 2100 (Fig. 15b). In contrast, emissions increased to almost $30 \mathrm{Pg} \mathrm{C} \mathrm{yr}^{-1}$ by the end of the century in the RCP8.5 scenario, resulting in a mole fraction of 1150 ppm (Figs. 15a,b). Between 2005 and 2100 global mean surface air temperature increased by $1.7 \mathrm{~K}$ in RCP4.5 and by $4.1 \mathrm{~K}$ in RCP8.5 (Fig. 15c). Increasing fossil fuel emissions and climatic changes led to changing patterns in fluxes with GPP, net primary production (NPP), and heterotrophic respiration increasing during the twenty-first century in both simulations (Figs. 15d,e), albeit at a reduced rate in the RCP4.5 simulation. These changes in ecosystem fluxes, as well as the prescribed reductions in land use change for RCP4.5, led to a net ecosystem carbon balance (NECB) lower than the contemporary value in RCP4.5, while the NECB increased in the RCP8.5 scenario (Fig. 15f). We discuss the effect of these changing fluxes on atmospheric $\mathrm{CO}_{2}$ in the following section.

\section{a. Twenty-first-century seasonal cycles}

The mean annual cycle in future atmospheric $\mathrm{CO}_{2}$ (2065-95) increased in both CESM RCP simulations relative to the contemporary period (1975-2005) (Fig. 16). At each of the sites in Fig. 16, the amplitude of the mean annual cycle increased in both scenarios relative to the contemporary period, although the changes were larger in RCP8.5.

The growth in the mean annual cycle had contributions from fossil, ocean, and land components. At all four sites, the fossil fuel contribution to seasonality was negligible in the historical simulation from 1975 to 2005 and in the RCP4.5 scenario where, from 2065 to 2095 , mean fossil fuel emissions were actually lower than contemporary emissions. In contrast, fossil fuel emissions contributed significantly to $\mathrm{CO}_{2}$ seasonality in the RCP8.5 scenario for 2065-95 (Figs. 16e-h). We caution that the seasonality of fossil fuel emissions in the RCP scenarios was derived from late-twentieth-century seasonal patterns scaled by the change in annual mean emissions, which resulted in increasing seasonality of emissions throughout the RCP8.5 scenario. In reality, energy use might show a smaller seasonal cycle in a warmer climate as, for example, winter heating burdens decrease and air conditioning demands increase during summer (Gregg et al. 2009).

The change in the mean annual cycle owing to ocean exchange was larger at high-latitude sites than at low-latitude sites (Figs. 16i-1). The ocean $\mathrm{CO}_{2}$ amplitude at both Barrow and the South Pole increased, and the phasing shifted toward earlier maxima and minima.

The terrestrial mean annual cycle amplitude increased in the Northern Hemisphere in both RCP simulations. The positive high-latitude trend in CESM during 19752005 (Table 6) remained steady during the RCP4.5 scenario. The trend in the seasonal amplitude at Barrow 


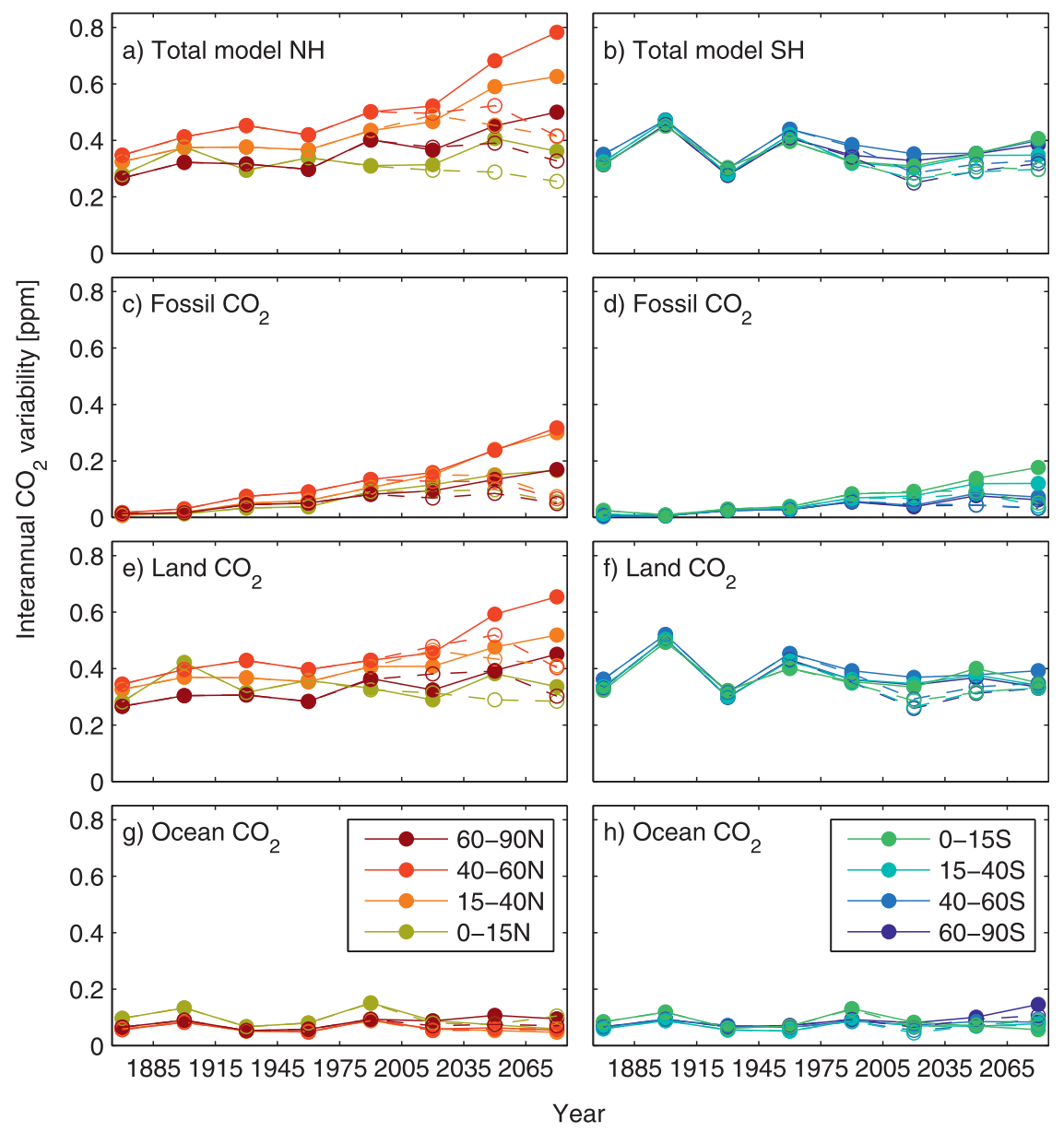

FIG. 14. Interannual variability (IAV) in surface $\mathrm{CESM} \mathrm{CO}_{2}$ for eight latitude bands in the (left) Northern Hemisphere and (right) Southern Hemisphere: (a),(b) IAV for the total $\mathrm{CO}_{2}$ in CESM, (c),(d) IAV for the fossil $\mathrm{CO}_{2}$ component, (e),(f) IAV for the land component of $\mathrm{CO}_{2}$, and $(\mathrm{g}),(\mathrm{h})$ IAV for the ocean component of $\mathrm{CO}_{2}$. The solid symbols show IAV from RCP8.5 and the open symbols show IAV from RCP4.5.

accelerated in RCP8.5, and the spring drawdown moved earlier in RCP8.5 relative to RCP4.5 (Fig. 16m). These changes in the seasonality in $\mathrm{CO}_{2}$ were due to an increase in net primary production during spring and summer at mid to high northern latitudes and a decrease in the seasonality of heterotrophic respiration. At Mauna Loa, the mean annual cycle amplitude of land $\mathrm{CO}_{2}$ increased by $28 \%$ from the contemporary period (1975-2005) to the end of the twenty-first century (2065-95) in the RCP8.5 scenario, in response to both land and fossil fuel influences (Fig. 16n). Gross primary production in CLM increased during summer by about $30 \%$, and the growing season onset occurred earlier in the spring at high northern latitudes. Heterotrophic respiration, which has a strong dependence on temperature, likewise increased in the annual mean, although its seasonality decreased throughout the twenty-first century in the RCP8.5 scenario, probably as a result of proportionally larger temperature increases during winter and spring. In the Southern Hemisphere, trends in the terrestrial contribution to the mean annual cycle were relatively small (Figs. 16o,p).

\section{b. Evolution of the north-south gradient}

The north-south gradient in $\mathrm{CO}_{2}$ continued to increase during the twenty-first century while fossil fuel emissions increased. The Mauna Loa-South Pole contrast grew from $3.2 \mathrm{ppm}$ in 2000 to $5.2 \mathrm{ppm}$ in 2050 in RCP4.5 but declined in the second half of the twenty-first century as emissions fell below the contemporary levels (Fig. 6a). In RCP8.5, the $\mathrm{CO}_{2}$ contrast between Mauna Loa and the South Pole grew to 14.2 ppm in 2100 (Fig. 6a).

Changes in atmosphere-ocean exchange also impacted the north-south gradient in the RCP simulations. 

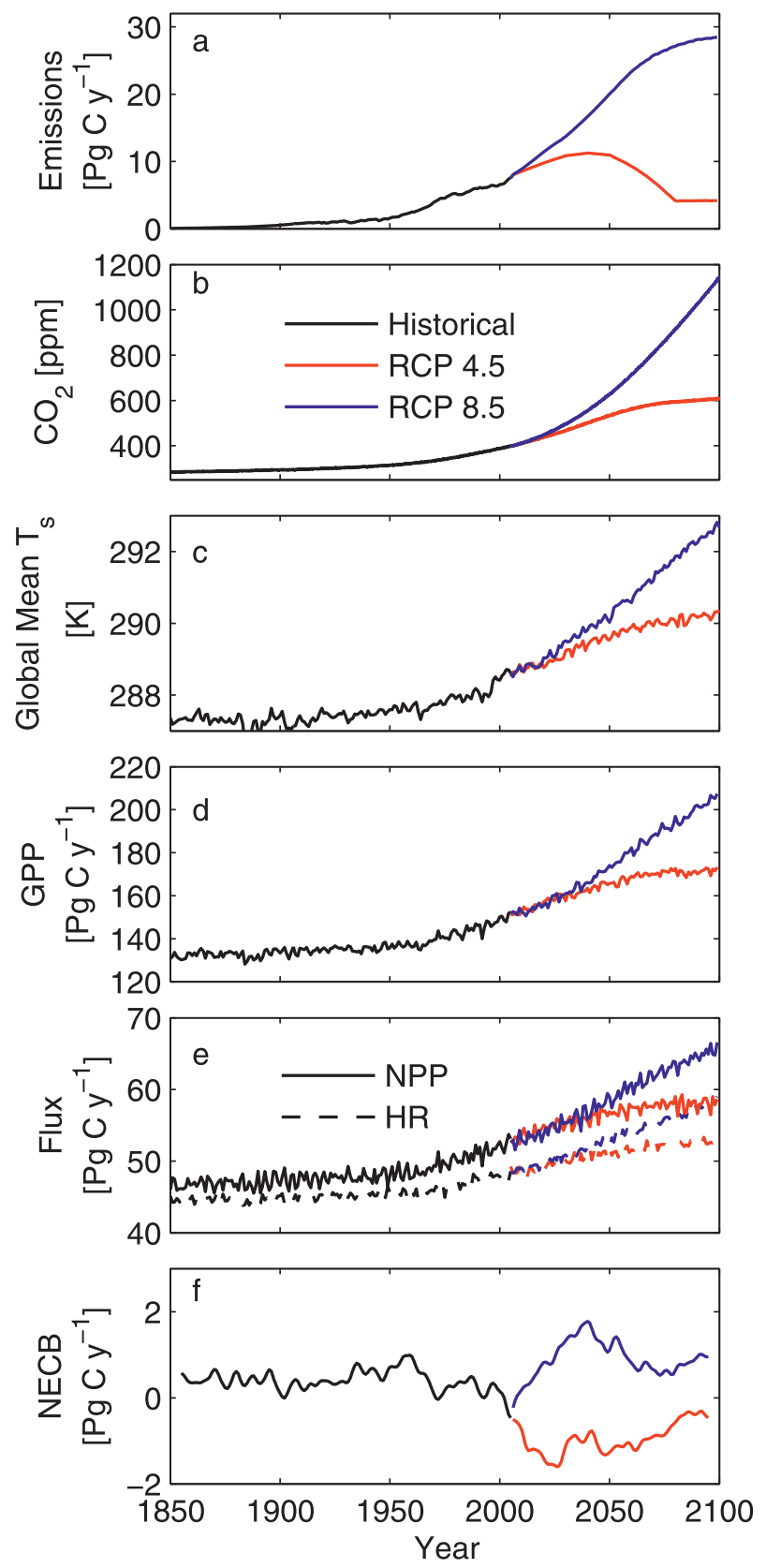

FIG. 15. Differences between the CESM RCP4.5 and RCP8.5 twenty-first-century scenarios: (a) annual mean global emissions for the historical simulation (1850-2005) (black) and for RCP4.5 (red) and RCP8.5 (blue) between 2005 and 2100; (b) monthly mean atmospheric $\mathrm{CO}_{2}$ sampled at Mauna Loa; (c) resulting global mean surface temperatures; (d) globally integrated and annually averaged gross primary production (GPP); (e) net terrestrial biospheric fluxes as net primary production (solid) and heterotrophic respiration (dashed). (f) Net ecosystem carbon balance (NECB) smoothed using a 10-yr filter, which represents the net land-to-atmosphere flux of $\mathrm{CO}_{2}$ in CESM including harvest, fire, and land use change.
The ocean component of $\mathrm{CO}_{2}$ decreased relative to the global mean between $40^{\circ}$ and $70^{\circ} \mathrm{S}$ (Fig. $6 \mathrm{c}$ ), consistent with a continued Southern Ocean sink for anthropogenic $\mathrm{CO}_{2}$, enhancing the total north-south gradient. Deep convective mixing and marine export production in the high-latitude North Atlantic were greatly reduced by the end of the century (Moore et al. 2012, manuscript submitted to J. Climate), weakening the ocean uptake of atmospheric $\mathrm{CO}_{2}$ in the Northern Hemisphere. The annual mean gradient owing to land fluxes showed the smallest changes in the twenty-first century (Fig. 6d), with increases smaller than $1 \mathrm{ppm}$ in the Northern Hemisphere midlatitudes at the end of the twenty-first century in RCP8.5.

\section{c. East-west gradients}

Monitoring east-west gradients in $\mathrm{CO}_{2}$ within the Northern or Southern Hemisphere may become increasingly important in the future for verification of $\mathrm{CO}_{2}$ emissions agreements. In this section, we discuss changes in both surface and column $\mathrm{CO}_{2}$ in relation to changing surface fluxes between the contemporary period (1975-2005) and the end of the RCP8.5 scenario (2065-95). For contemporary conditions, the most noticeable signal in east-west gradients in surface $\mathrm{CO}_{2}$ was the $\mathrm{CO}_{2}$ enhancement over tropical land relative to the oceans due to increases in photosynthesis and nighttime trapping of respired $\mathrm{CO}_{2}$ in a stable boundary layer (Fig. 17a). Enhancements in surface $\mathrm{CO}_{2}$ also occurred over the industrialized regions of Europe, East Asia, and eastern North America. Notably, column $\mathrm{CO}_{2}$ changes were negligible in the tropics (Fig. 17d), while the eastwest gradients caused by fossil fuel emissions in the Northern Hemisphere were still apparent.

East-west gradients at the surface increased by the end of the twenty-first century in the RCP 8.5 scenario in northern midlatitudes and in the tropics (Figs. 17b,c). In northern midlatitudes, much of the increase in landocean $\mathrm{CO}_{2}$ differences by 2100 appeared to be linked with increases in fossil fuel emissions, as described above in section 3e. In the tropics, in contrast, enhancements in surface $\mathrm{CO}_{2}$ over forests were not matched by column $\mathrm{CO}_{2}$ increases (Figs. 17e,f), suggesting that the increases at the surface were due primarily to the rectifier effect operating on larger gross fluxes (Figs. 15d,e) rather than changing net fluxes (Chapin et al. 2006). We examined GPP, ecosystem respiration, and net land-use change fluxes and found that GPP fluxes increased by about $25 \%$ throughout the tropics. The total carbon loss from land use change in CESM decreased by about $40 \%$ for the Amazon at the end of the twenty-first century relative to 1975-2005 in RCP8.5, also confirming that the changes in tropical surface mole fractions were due to 
Total
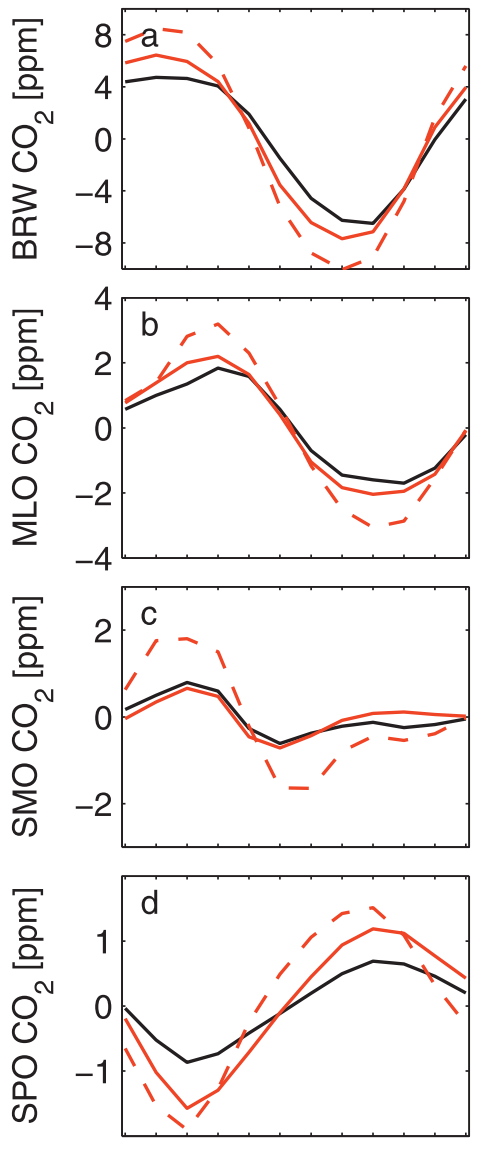

JFMAMJ JASOND
Fossil
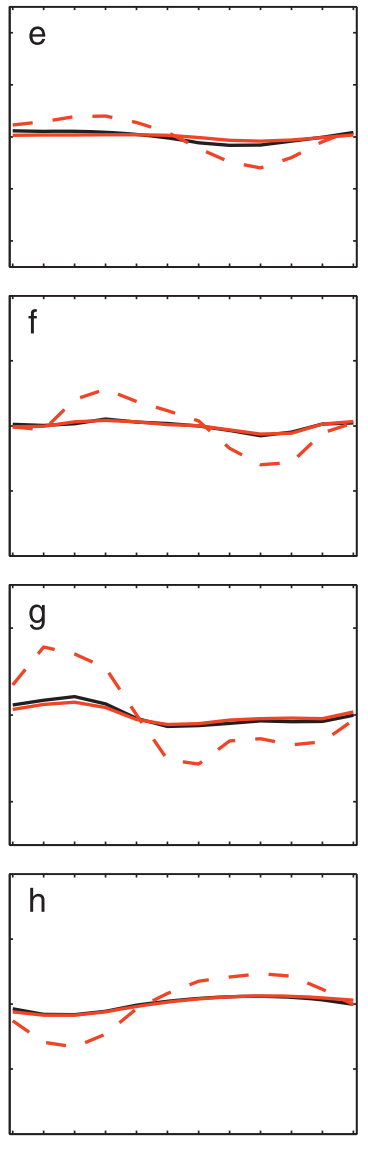

Ocean
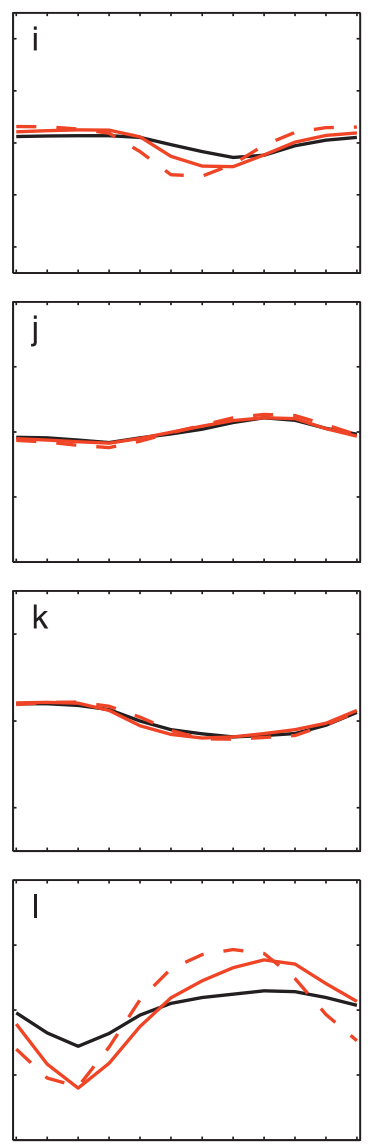

JFMAMJ JASOND
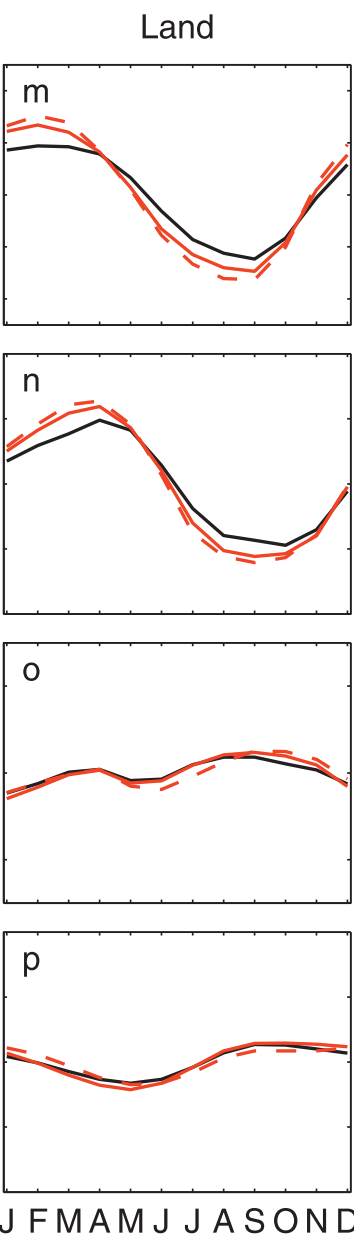

Month

FIG. 16. Simulated mean annual cycle in atmospheric $\mathrm{CO}_{2}$ at four GMD sites: Barrow (BRW), Mauna Loa (MLO), Samoa (SMO), and the South Pole (SPO) for 1975-2005 (historical simulation) and the later part of the twenty-first century (RCP4.5 and RCP8.5). The seasonal cycle in total $\mathrm{CO}_{2}$ is separated into its fossil, ocean, and land components. Note the change of scale for the $y$ axis for each site.

rectifier effects. For tropical Africa the integrated carbon loss due to land use change was higher by a factor of 6 compared to the period from 1975 to 2005 but still constituted a small enough source that it did not lead to observable east-west gradients in the column.

Fossil fuel emissions increased significantly in the $\mathrm{RCP} 8.5$ scenario and were a primary driver of the changes in the east-west column $\mathrm{CO}_{2}$ gradients in northern midlatitudes. The east-west gradients in the column increased considerably from China to the mid Pacific over the twenty-first century. Specifically, column differences between the NOAA Tae-Ahn peninsula site $\left(36^{\circ} \mathrm{N}\right.$, $\left.126^{\circ} \mathrm{E}\right)$ and the mid-Pacific $\left(36^{\circ} \mathrm{N}, 155^{\circ} \mathrm{W}\right)$ increased from 0.5 ppm during 1975-2005 to 2.6 ppm during 2065-95.

We also quantified the trend in the surface enhancement relative to SPO at Tae-Ahn and the three background sites explored in section $3 \mathrm{e}$ with respect to fossil fuel emissions from China for the two emission scenarios (Figs. 13b,c). All four sites showed a linear trend with respect to Chinese emissions, even while emissions decreased and the difference in $\mathrm{CO}_{2}$ at each site relative to the South Pole declined at the end of the RCP4.5 simulation. The linear regression slope of the Tae-Ahn to $\mathrm{SPO} \mathrm{CO}_{2}$ gradient versus Chinese emissions was $5.0 \pm$ $0.5 \mathrm{ppm}\left(\mathrm{Pg} \mathrm{C} \mathrm{yr}^{-1}\right)^{-1}$ higher than the slopes computed from neighboring sites (at similar latitudes) in both simulations. The relative slopes were similar in both RCP4.5 and RCP 8.5 because emissions from China accounted for about $25 \%$ of global emissions in both scenarios over the twenty-first century, compared to about $20 \%$ in 2005 . China's contribution to global emissions increased rapidly at the beginning of the RCP4.5 scenario and peaked 

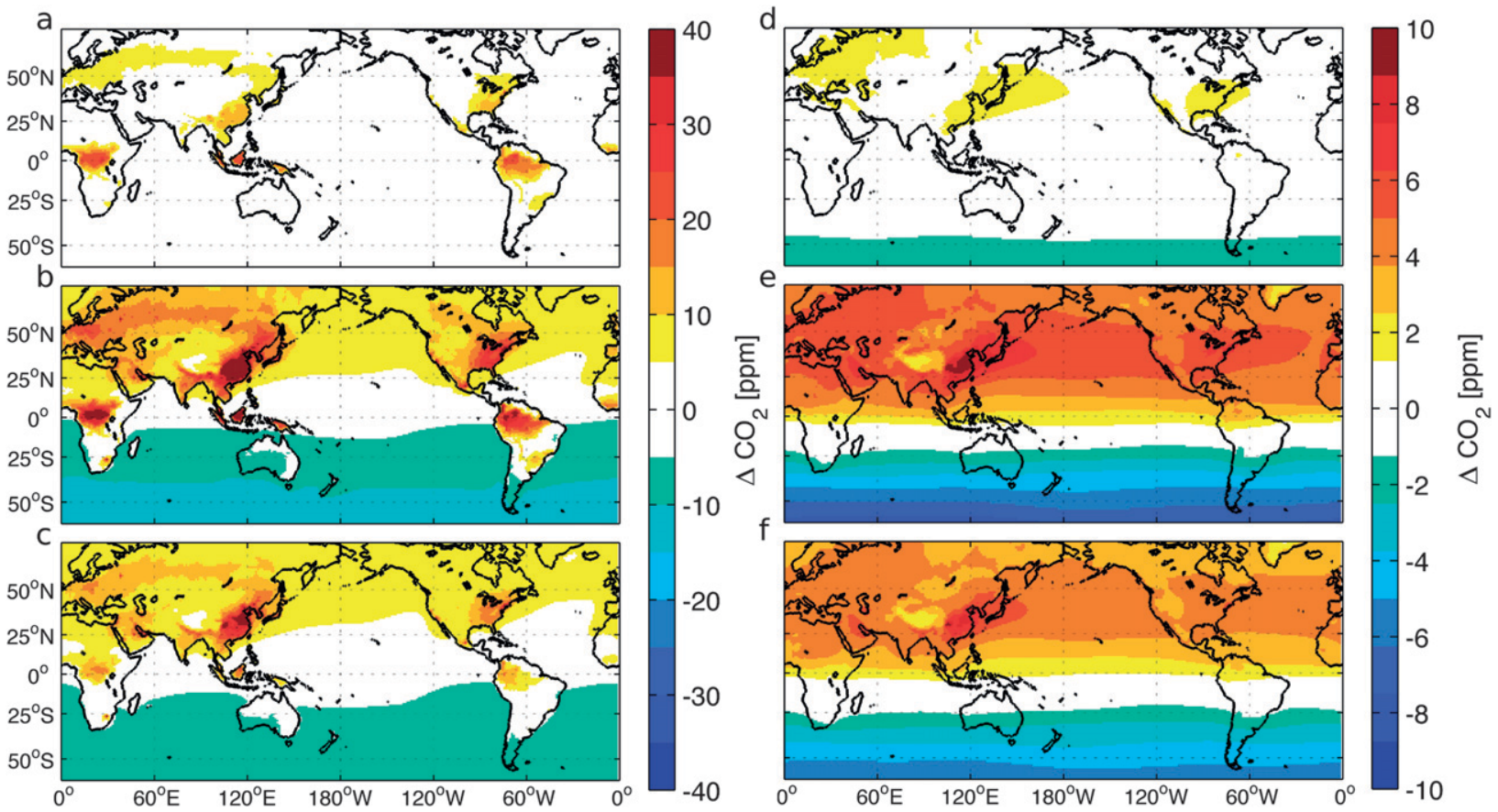

FIG. 17. Distribution of mean surface and column $\mathrm{CO}_{2}$ in the CESM. Time mean surface $\mathrm{CO}_{2}$ fields relative to the global mean (a) for 1975-2005 and (b) for 2065-95 in the RCP8.5 scenario, and (c) difference for the two time periods for the surface layer. Time mean column $\mathrm{CO}_{2}$ fields relative to the global mean (d) for 1975-2005 and (e) for 2065-95 in the RCP8.5 scenario, and (f) difference for the two time periods for the total column.

at $30 \%$ in 2050 . During the latter half of the twenty-firstcentury, Chinese emissions and the Tae-Ahn to $\mathrm{SPO} \mathrm{CO}$ gradient decreased in $\mathrm{RCP} 4.5$ but remained on the same trend line as for the first half of the century, shown in Fig. 13b.

The interannual variability in the growth rate at TaeAhn also was greater than at the northern midlatitude background stations, as shown in Fig. 13, likely because of this station's proximity to source regions and, thus, for year to year differences in meteorology to modify large $\mathrm{CO}_{2}$ spatial gradients (Turnbull et al. 2011). This high level of variability may complicate the use of atmospheric observations to infer surface fluxes (National Research Council 2010). We note that RCP4.5 and RCP8.5 represented only two possible trajectories for atmospheric $\mathrm{CO}_{2}$ and that simulated spatial gradients were sensitive to the prescribed distribution of emissions across different countries and regions. Further examination of the differences in east-west gradients in atmospheric $\mathrm{CO}_{2}-$ both at the surface and through the free tropospherebetween scenarios with similar emissions but different geographic distributions is needed to determine at what point the current observational network can detect changes in regional fossil fuel emissions and to determine how best to improve the observational network such that emissions from China, for example, can be distinguished from emissions originating from other countries within East Asia.

\section{d. Interannual variability}

In the RCP4.5 scenario, interannual variability (IAV) did not significantly change during the twenty-first century in either the Northern or Southern Hemispheres (Fig. 14). In contrast, Northern Hemisphere IAV in $\mathrm{CO}_{2}$ increased throughout the RCP8.5 scenario, driven by increasing variability in fossil fuel and land fluxes. In general, increasing interannual variability can be caused by increases in the variability of atmospheric circulation, increased variability in surface fluxes, or larger $\mathrm{CO}_{2}$ gradients (likely from increases in fossil fuel emissions) interacting with atmospheric mixing processes that may or may not change significantly with climate warming. In the case of fossil fuel IAV, it is likely that some of the increase was caused by transport acting on larger atmospheric gradients since the prescribed fossil fuel emissions were smooth in time. In the case of land $\mathrm{CO}_{2}$, all three of the mechanisms described above may have contributed to the positive trend. Globally integrated terrestrial GPP increased during the twenty-first century in both scenarios (Fig. 15d), as did the Northern Hemisphere growing season length; in response, periods of drought and temperature stress induced larger year to 
year variations in surface fluxes (data not shown). Moreover, climate under global warming should be characterized by more variability and larger extremes (Coumou and Rahmstorf 2012). We did not attempt to further separate these contributions here because multiple simulations would be needed to characterize how extreme climate events changed over time; an ensemble of simulations was not available for these RCP scenarios.

The simulated increase in IAV in land $\mathrm{CO}_{2}$ was due to interannual variability in ecosystem exchange rather than changes in land use, since the latter fluxes were one to two orders of magnitude smaller for key regions such as the Amazon, and prescribed changes in land cover changed only gradually from year to year. The largest changes in GPP occurred in the tropics, South Asia, and Siberia. In the tropics, increases in GPP IAV were spatially correlated with increased IAV in precipitation, whereas in the extratropics simulated increases in GPP IAV were more strongly correlated with surface air temperature. More process-level understanding could be gained by analyzing flux IAV in smaller, ecologically coherent regions. That analysis, however, is outside the scope of this paper.

\section{Discussion and implications for carbon cycle science}

Over the last half century, the growth rate of atmospheric $\mathrm{CO}_{2}$ was higher in the model than in observations, suggesting that the overall sensitivity of land and ocean $\mathrm{CO}_{2}$ uptake to rising atmospheric $\mathrm{CO}_{2}$ (and other human global change perturbations) was too weak. Lindsay et al. (2012, manuscript submitted to J. Climate) show that the land sink in CESM1-BGC was too weak during the last several decades. Part of this may be due to the fact that the photosynthetic parameter $\mathrm{Vc}_{\max }$ is too low when down-regulated by nitrogen in CLM (Randerson et al. 2009; Bonan et al. 2011), which reduces the sensitivity of photosynthesis to higher ambient $\mathrm{CO}_{2}$ concentrations. Todd-Brown et al. (2013) also show that soil carbon in CCSM4, the predecessor to CESM, was approximately a factor of 2 lower than the Harmonized World Soil Database global estimate and was over a factor of 8 lower than the HWSD inventory at high latitudes. These findings suggest that soil turnover may occur too rapidly in CESM, further limiting rates of carbon accumulation in response to elevated $\mathrm{CO}_{2}$ and other environmental factors that may be increasing net primary production. Patterns of variation in atmospheric $\mathrm{CO}_{2}$ suggest that ocean uptake patterns also contributed to some of the CESM bias. Long et al. (2013) show that the ocean carbon inventory is low by $14 \%$ in the coupled model, while Wang et al. (2012) find that ocean anthropogenic carbon inventory in CCSM-3 (the predecessor to CESM1-BGC) is low by $20 \%$.

Weak overturning of water masses in the Southern Ocean likely explain both the small ocean sink in CESM and the mismatch in the inferred preindustrial interhemispheric $\mathrm{CO}_{2}$ gradient documented here. Long et al. (2013) investigate the uptake of atmospheric $\mathrm{CO}_{2}$ by the world's oceans and find that, while fluxes of $\mathrm{CO}_{2}$ into the Southern Ocean are larger than observed, the inventory of anthropogenic $\mathrm{CO}_{2}$ is too low due to weak formation rates of Antarctic Intermediate Water and Subantarctic Mode Water. This result is corroborated by Weijer et al. (2012), who show that CFC enhancements do not penetrate below the mixed layer as much as indicated by observations. Weak exchange between the surface and deeper water masses subsequently results in low sequestration of anthropogenic $\mathrm{CO}_{2}$ and reduced outgassing of natural $\mathrm{CO}_{2}$ from the deeper water masses. Analysis of changing north-south contrasts in atmospheric $\mathrm{CO}_{2}$ and $\delta^{13} \mathrm{C}$ suggest that the stationary gradient in atmospheric $\mathrm{CO}_{2}$ is determined mostly by ocean fluxes, corroborating our result (Keeling et al. 2011). Long et al. (2013), however, also show that the ocean anthropogenic carbon inventory is low elsewhere, including the North Atlantic, which may be due to bias in the formation of mode and intermediate waters.

Land fluxes in CESM contributed to discrepancies between atmospheric $\mathrm{CO}_{2}$ in CESM and observations on shorter time scales, with implications for sources and sinks and the sensitivity of these carbon fluxes to climate change. Weak mean annual cycle amplitudes in atmospheric $\mathrm{CO}_{2}$ throughout the Northern Hemisphere and weak equator-to-pole $\mathrm{CO}_{2}$ gradients during the Northern Hemisphere growing season provided evidence that the growing season net flux is too small in CESM. This phenomenon was noted in an analysis of TCCON total column data for other land models, and atmospheric tracer simulations with net ecosystem production flux perturbations show that weak growing season fluxes in boreal ecosystems are the cause (Keppel-Aleks et al. 2012). From the mass constraints provided by column observations, we infer that the CESM growing season net flux in the Northern Hemisphere was too small by $40 \%-60 \%$, with much of this deficiency in boreal or temperate forest ecosystems. Part of this discrepancy could be due to biases in the climate driving the CESM land fluxes: P. J. Lawrence et al. (2012) show that the simulated seasonal cycle in temperature in high-latitude regions generally agrees with observations, although precipitation is slightly too high. Simulations with CLM driven by historical climate patterns are underway as part of the Trendy analysis project and will allow us to 
quantify the effects of the CESM climate on the coupled system. Rapid turnover of soil carbon, consistent with simulated soil carbon inventory at high latitudes being only about $10 \%$ of observations (Todd-Brown et al. 2013), may also have contributed to the small seasonality since more rapid cycling of summer polarorbitng NPP inputs within labile litter and soil pools could potentially offset simultaneous carbon gains from photosynthesis. Given that high latitudes are expected to experience amplified warming (e.g., Holland and Bitz 2003), it is crucial that coupled models such as CESM capture the mechanics of land fluxes within these ecosystems, including permafrost hydrology (D. M. Lawrence et al. 2012) and carbon processes (Koven et al. 2011).

The early onset of the Northern Hemisphere growing season potentially has important implications for the climate response of CESM to further warming during spring. P. J. Lawrence et al. (2012) show that seasonal patterns in land surface temperature are well represented in the Northern Hemisphere, suggesting that model deficiencies in the representation of phenology or cold hardening processes in conifers are more likely to be primary drivers than biases in climate. Richardson et al. (2012) found that many biogeochemical models simulate early onset to growing season because phenology is inaccurately parameterized. Since accurate representation of model phenology is crucial for partitioning fluxes of energy and for determining the sensitivity of vegetation to climate stressors (Richardson et al. 2012), we recommend further analysis and refinement of phenology algorithms in CLM.

The diagnostics that we have developed in this paper provide a means to test future generations of coupled carbon-climate models. Because most $\mathrm{CO}_{2}$ observations, including those with the longest observational records, are made within the atmospheric boundary layer, most model evaluation has been conducted against this type of observation (e.g., Cadule et al. 2010). By extending our analysis to column and free tropospheric observations, we were able to more thoroughly examine the fluxes and atmospheric physics in CESM. We could not positively establish whether a vertical transport bias in CESM contributed to the weak vertical gradients in the model relative to aircraft observations because the mean annual cycle at the surface and at all layers was set by the interplay of fluxes (which were established by the comparison with column observations to be too weak) and transport. We suggest that more careful analysis of the vertical distribution of water vapor, carbon isotopes, and other regional carbon tracers in CAM would be useful for evaluating the vertical mixing parameterization on seasonal time scales, in addition to adding passive tracers such as radon or $\mathrm{SF}_{6}$ (e.g., Denning et al. 1999).
The CESM simulations analyzed here indicated that patterns of variability in atmospheric $\mathrm{CO}_{2}$ during the twenty-first century will likely depend on future climate forcing and $\mathrm{CO}_{2}$ emissions. CESM simulated plausible increases in the mean annual cycle and north-south and east-west gradients during the twenty-first century, but the magnitude of these increases should be considered as having large uncertainties owing to the model's bias toward low temporal variability in the historical simulation. CESM simulations of the twenty-first century showed the mean annual cycle amplitude increasing in all latitude bands, with the magnitude of the increase affected by climatic changes, emission rates, and atmospheric $\mathrm{CO}_{2}$ levels. Although these simulations provided evidence that the shape of the mean annual cycle will continue to change, with a trend toward earlier drawdown of $\mathrm{CO}_{2}$ in the spring, this result must be considered in light of the bias in the timing of the growing season onset that we documented for CESM during the contemporary period.

Although both RCP4.5 and RCP8.5 simulations show increased interannual variability in fossil $\mathrm{CO}_{2}$ at all latitude bands, interannual variability in land and ocean $\mathrm{CO}_{2}$ varied considerably as a function of latitude and between the two scenarios. Some of the increased variability may be due to atmospheric dynamics interacting with larger spatial gradients: small interannual shifts in the position of the jet stream, for instance, may change the origin of $\mathrm{CO}_{2}$ sampled at a given observatory significantly. We propose more in-depth analysis to determine how both atmospheric dynamics and fluxes may change in the future so that monitoring networks can be optimized to discern such variability from interannual trends.

Changes in regional $\mathrm{CO}_{2}$ patterns over source regions may be one of the fingerprints by which we can potentially monitor fossil fuel emissions (National Research Council 2010). Here we showed that temporal variability in atmospheric $\mathrm{CO}_{2}$ increased as a function of fossil fuel emissions, with IAV changes in the RCP8.5 scenario outpacing those in the RCP4.5 scenario. As patterns in spatial and interannual variability change, interpretation of atmospheric observations may become more complicated and may require different observational strategies to extract information pertaining to fossil fuel emissions and terrestrial and ocean exchange. We note that the spatial coverage of $\mathrm{CO}_{2}$ observations is expected to increase markedly in the coming decades as satellite missions using a variety of sensing methods and orbital geometries come online and as routine aircraft sampling of atmospheric $\mathrm{CO}_{2}$ increases. Monitoring of $\mathrm{CO}_{2}$ in urban areas also is likely to expand in the coming decades (Duren and Miller 2012). An expanded suite of 
atmospheric tracer observations, including, for example, $\mathrm{O}_{2}: \mathrm{N}_{2}$ ratios, ${ }^{13} \mathrm{C}$ and ${ }^{14} \mathrm{C}$ isotopes, and coemitted species like $\mathrm{CO}$ and $\mathrm{CH}_{4}$, will also be crucial for attributing changing patterns in atmospheric $\mathrm{CO}_{2}$ to natural and anthropogenic causes.

Acknowledgments. The CESM project is supported by the National Science Foundation and the Office of Science (BER) of the U.S. Department of Energy. Computing resources were provided by the Climate Simulation Laboratory at NCAR's Computational and Information Systems Laboratory (CISL), sponsored by the National Science Foundation and other agencies. G.K.A. acknowledges support of a NOAA Climate and Global Change postdoctoral fellowship. J.T.R., N.M.M., S.C.D., K.L., and J.K.M. acknowledge support of Collaborative Research: Improved Regional and Decadal Predictions of the Carbon Cycle (NSF AGS-1048827, AGS-1021776, AGS-1048890). The HIPPO Program was supported by NSF Grants ATM-0628575, ATM-0628519, and ATM-0628388 to Harvard University, University of California (San Diego), and by University Corporation for Atmospheric Research, University of Colorado/ CIRES, by the NCAR and by the NOAA Earth System Research Laboratory. Sunyoung Park, Greg Santoni, Eric Kort, and Jasna Pittman collected data during HIPPO. The ACME project was supported by the Office of Biological and Environmental Research of the U.S. Department of Energy under Contract DE-AC0205CH11231 as part of the Atmospheric Radiation Measurement Program (ARM), the ARM Aerial Facility, and the Terrestrial Ecosystem Science Program. TCCON measurements at Eureka were made by the Canadian Network for Detection of Atmospheric Composition Change (CANDAC) with additional support from the Canadian Space Agency. The Lauder TCCON program was funded by the New Zealand Foundation for Research Science and Technology contracts CO1X0204, CO1X0703, and CO1X0406. Measurements at Darwin and Wollongong were supported by Australian Research Council Grants DP0879468 and DP110103118 and were undertaken by David Griffith, Nicholas Deutscher, and Ronald Macatangay. We thank Pauli Heikkinen, Petteri Ahonen, and Esko Kyrö of the Finnish Meteorological Institute for contributing the Sodankylä TCCON data. Measurements at Park Falls, Lamont, and Pasadena were supported by NASA Grant NNX11AG01G and the NASA Orbiting Carbon Observatory Program. Data at these sites were obtained by Geoff Toon, JeanFrancois Blavier, Coleen Roehl, and Debra Wunch. We are grateful to the DOE ARM program for technical support in Lamont and Jeff Ayers for technical support at Park Falls. Complete acknowledgments for all sites can be found on the TCCON website: https://tcconwiki.caltech.edu/Network_Policy/Data_Use_Policy.

\section{REFERENCES}

Andres, R. J., J. S. Gregg, L. Losey, G. Marland, and T. A. Boden, 2011: Monthly, global emissions of carbon dioxide from fossil fuel consumption. Tellus, 63B, 309-327, doi:10.1111/ j.1600-0889.2011.00530.x.

Arora, V. K., and A. Montenegro, 2011: Small temperature benefits provided by realistic afforestation efforts. Nat. Geosci., 8 , 514-518, doi:10.1038/ngeo1182.

Bacastow, R. B., 1976: Modulation of atmospheric carbon dioxide by the Southern Oscillation. Nature, 261, 116-118.

Biraud, S. C., M. S. Torn, J. R. Smith, C. Sweeney, W. J. Riley, and P. P. Tans, 2013: A multi-year record of airborne $\mathrm{CO}_{2}$ observations in the US southern Great Plains. Atmos. Meas. Tech., 6, 751-763, doi:10.5194/amt-6-751-2013.

Boden, T. A., G. Marland, and R. J. Andres, 2009: Global, regional, and national fossil-fuel $\mathrm{CO}_{2}$ emissions. Tech. Rep., Carbon Dioxide Information Analysis Center, Oak Ridge National Laboratory, U.S. Department of Energy, Oak Ridge, TN, doi:10.3334/CDIAC/00001.

Bonan, G., P. J. Lawrence, K. W. Oleson, S. Levis, M. Jung, M. Reichstein, D. M. Lawrence, and S. C. Swenson, 2011: Improving canopy processes in the Community Land Model version 4 (CLM4) using global flux fields empirically inferred from FLUXNET data. J. Geophys. Res., 116, G02014, doi:10.1029/ 2010JG001593.

Cadule, P., and Coauthors, 2010: Benchmarking coupled climatecarbon models against long-term atmospheric $\mathrm{CO}_{2}$ measurements. Global Biogeochem. Cycles, 24, GB2016, doi:10.1029/ 2009GB003556.

Canadell, J. G., and Coauthors, 2007: Contributions to accelerating atmospheric $\mathrm{CO}_{2}$ growth from economic activity, carbon intensity, and efficiency of natural sinks. Proc. Natl. Acad. Sci. USA, 104, 18 866-18 870, doi:10.1073/pnas.0702737104.

Chapin, F. S., III, and Coauthors, 2006: Reconciling carbon cycle concepts, terminology, and methodology. Ecosystems, 9, 1041-1050.

Chen, Y., and Coauthors, 2011: Forecasting fire season severity in South America using sea surface temperature anomalies. Science, 334, 787-791, doi:10.1126/science.1209472.

Ciais, P., and Coauthors, 2005: Europe-wide reduction in primary productivity caused by the heat and drought in 2003. Nature, 437, 529-533, doi:10.1038/nature03972.

Cleveland, W. S., A. E. Freeny, and T. E. Graedel, 1983: The seasonal component of atmospheric $\mathrm{CO}_{2}$ : Information from new approaches to the decomposition of seasonal time series. J. Geophys. Res., 88, 10 934-10946.

Conway, T. J., and P. P. Tans, 1999: Development of the $\mathrm{CO}_{2}$ latitude gradient in recent decades. Global Biogeochem. Cycles, 13, 821-826.

,-- L. S. Waterman, and K. W. Thoning, 1994: Evidence for interannual variability of the carbon cycle from the National Oceanic and Atmospheric Administration Climate Monitoring and Diagnostics Laboratory global air sampling network. J. Geophys. Res., 99, 22 831-22 855.

Coumou, D., and S. Rahmstorf, 2012: A decade of weather extremes. Nat. Climate Change, 2, 491-496, doi:10.1038/nclimate1452.

Crevoisier, C., C. Sweeney, M. Gloor, J. L. Sarmiento, and P. P. Tans, 2010: Regional US carbon sinks from three-dimensional 
atmospheric $\mathrm{CO}_{2}$ sampling. Proc. Natl. Acad. Sci. USA, 107, 18 348-18 353, doi:10.1073/pnas.0900062107.

Danabasoglu, G., S. C. Bates, B. P. Briegleb, S. R. Jayne, M. Jochum, W. G. Large, S. Peacock, and S. G. Yeager, 2011: The CCSM4 ocean component. J. Climate, 25, 1361-1389.

Denning, A. S., I. Y. Fung, and D. Randall, 1995: Latitudinal gradient of atmospheric $\mathrm{CO}_{2}$ due to seasonal exchange with land biota. Nature, 376, 240-243.

— , and Coauthors, 1999: Three-dimensional transport and concentration of $\mathrm{SF}_{6}$. Tellus, 51B, 266-297, doi:10.1034/ j.1600-0889.1999.00012.x.

Deser, C., and Coauthors, 2012: ENSO and Pacific decadal variability in Community Climate System Model version 4. J. Climate, 25, 2622-2651.

Deutscher, N. M., and Coauthors, 2010: Total column $\mathrm{CO}_{2}$ measurements at Darwin, Australia-Site description and calibration against in situ aircraft profiles. Atmos. Meas. Tech., 3, 947-958.

Doney, S. C., K. Lindsay, I. Fung, and J. John, 2006: Natural variability in a stable, 1000-yr global coupled climate-carbon cycle simulation. J. Climate, 19, 3033-3054.

_ I. Lima, R. A. Feely, D. M. Glover, K. Lindsay, N. Mahowald, J. K. Moore, and R. Wanninkhof, 2009: Mechanisms governing interannual variability in upper-ocean inorganic carbon system and air-sea $\mathrm{CO}_{2}$ fluxes: Physical climate and atmospheric dust. Deep-Sea Res. II, 56, 640-655.

Duren, R. M., and C. M. Miller, 2012: Measuring the carbon emissions of megacities. Nat. Climate Change., 2, 560-562.

Fan, S. M., S. C. Wofsy, P. S. Bakwin, D. J. Jacob, and D. R. Fitzjarrald, 1990: Atmosphere-biosphere exchange of $\mathrm{CO}_{2}$ and $\mathrm{O}_{3}$ in the central Amazon forest. J. Geophys. Res., 95, $16851-16864$.

Finzi, A. C., J. J. Cole, S. C. Doney, E. A. Holland, and R. B. Jackson, 2011: Research frontiers in the analysis of coupled biogeochemical cycles. Front. Ecol. Environ, 9, 74-80, doi:10.1890/100137.

Friedlingstein, P., and Coauthors, 2006: Climate-carbon cycle feedback analysis: Results from the C4MIP model Intercomparison. J. Climate, 19, 3337-3353.

Fung, I. Y., S. C. Doney, K. Lindsay, and J. John, 2005: Evolution of carbon sinks in a changing climate. Proc. Natl. Acad. Sci. USA, 102, 11 201-11 206, doi:10.1073/pnas.0504949102.

Gent, P. R., and Coauthors, 2011: The Community Climate System Model version 4. J. Climate, 24, 4973-4991.

Golding, N., and R. Betts, 2008: Fire risk in Amazonia due to climate change in the HadCM3 climate model: Potential interactions with deforestation. Global Biogeochem. Cycles, 22, GB4007, doi:10.1029/2007GB003166.

Gregg, J. S., L. M. Losey, R. J. Andres, T. J. Blasing, and G. Marland, 2009: The temporal and spatial distribution of carbon dioxide emissions from fossil-fuel use in North America. J. Appl. Meteor. Climatol., 48, 2528-2542.

Gurney, K. R., and Coauthors, 2002: Towards robust regional estimates of $\mathrm{CO}_{2}$ sources and sinks using atmospheric transport models. Nature, 415, 626-630.

Heimann, M., and C. D. Keeling, 1986: Meridional eddy diffusion model of the transport of atmospheric carbon dioxide 1. Seasonal carbon cycle over the tropical Pacific Ocean. J. Geophys. Res., 91, 7765-7781.

Holland, M. M., and C. M. Bitz, 2003: Polar amplification of climate change in coupled models. Climate Dyn., 21, 221-232.

Jacobson, A. R., S. E. M. Fletcher, N. Gruber, J. L. Sarmiento, and M. Gloor, 2007: A joint atmosphere-ocean inversion for surface fluxes of carbon dioxide: 1 . Methods and global-scale fluxes. Global Biogeochem. Cycles, 21, GB1019, doi:10.1029/ $2005 \mathrm{~GB} 002556$.

Jones, C. D., M. Collins, P. M. Cox, and S. A. Spall, 2001: The carbon cycle response to ENSO: A coupled climate-carbon cycle model study. J. Climate, 14, 4113-4129.

Keeling, C. D., J. F. S. Chin, and T. P. Whorf, 1996: Increased activity of northern vegetation inferred from atmospheric $\mathrm{CO}_{2}$ measurements. Nature, 382, 146-149.

, S. C. Piper, R. B. Bacastow, M. Wahlen, T. P. Whorf, M. Heimann, and H. A. Meijer, 2001: Exchanges of atmospheric $\mathrm{CO}_{2}$ and ${ }^{13} \mathrm{CO}_{2}$ with the terrestrial biosphere and oceans from 1978 to 2000. SIO Reference Series Rep. 01-06, Scripps Institution of Oceanography, $88 \mathrm{pp}$.

, — - T. P. Whorf, and R. Keeling, 2011: Evolution of natural and anthropogenic fluxes of atmospheric $\mathrm{CO}_{2}$ from 1957 to 2003. Tellus, 63B, 1-22, doi:10.1111/j.1600-0889.2010.00507.x.

Keeling, R. F., S. C. Piper, and M. Heimann, 1996: Global and hemispheric $\mathrm{CO}_{2}$ sinks deduced from changes in atmospheric $\mathrm{O}_{2}$ concentration. Nature, 381, 218-221.

Keppel-Aleks, G., P. O. Wennberg, and T. Schneider, 2011: Sources of variations in total column carbon dioxide. Atmos. Chem. Phys., 11, 3581-3593.

_ transport on variations in total column carbon dioxide. Biogeosciences, 9, 875-891.

Khatiwala, S., F. Primeau, and T. Hall, 2009: Reconstruction of the history of anthropogenic $\mathrm{CO}_{2}$ concentrations in the ocean. Nature, 462, 346-U110, doi:10.1038/nature08526.

Kloster, S., and Coauthors, 2010: Fire dynamics during the 20th century simulated by the Community Land Model. Biogeosciences, 7, 1877-1902, doi:10.5194/bg-7-1877-2010.

Koven, C. D., B. Ringeval, P. Friedlingstein, P. Ciais, P. Cadule, D. Khvorostyanov, G. Krinner, and C. Tarnocai, 2011: Permafrost carbon-climate feedbacks accelerate global warming. Proc. Natl. Acad. Sci. USA, 108, 14 769-14 774, doi:10.1073/ pnas.1103910108.

Lamarque, J.-F., and Coauthors, 2010: Historical (1850-2000) gridded anthropogenic and biomass burning emissions of reactive gases and aerosols: Methodology and application. Atmos. Chem. Phys., 10, 7017-7039.

Law, R. M., L. P. Steele, P. B. Krummel, and W. Zahorowski, 2010: Synoptic variations in atmospheric $\mathrm{CO}_{2}$ at Cape Grim: A model intercomparison. Tellus, 62B, 810-820, doi:10.1111/ j.1600-0889.2010.00470.x.

Lawrence, D. M., K. W. Oleson, M. G. Flanner, C. G. Fletcher, P. J. Lawrence, S. Levis, S. C. Swenson, and G. B. Bonan, 2012: The CSM4 land simulation, 1850-2005: Assessment of surface climate and new capabilities. J. Climate, 25, 2240-2260, doi:10.1175/JCLI-D-11-00103.1.

Lawrence, P. J., and Coauthors, 2012: Simulating the biogeochemical and biogeophysical impacts of transient land cover change and wood harvest in the Community Climate System Model (CCSM4) from 1850 to 2100. J. Climate, 25, 30713095.

Le Quéré, C., and Coauthors, 2007: Saturation of the Southern Ocean $\mathrm{CO}_{2}$ sink due to recent climate change. Science, 316, 1735-1738, doi:10.1126/science.1136188.

— carbon dioxide. Nat. Geosci., 2, 831-836, doi:10.1038/ngeo689.

Long, M., K. Lindsay, S. Peacock, J. K. Moore, and S. C. Doney, 2013: Twentieth-century oceanic carbon uptake and storage in CESM1-BGC. J. Climate, in press. 
Lovenduski, N. S., and T. Ito, 2009: The future evolution of the southern ocean $\mathrm{CO}_{2}$ sink. J. Mar. Res., 67, 597-617.

—, N. Gruber, and S. C. Doney, 2008: Toward a mechanistic understanding of the decadal trends in the Southern Ocean carbon sink. Global Biogeochem. Cycles, 22, GB3016, doi:10.1029/ 2007GB003139.

Matsueda, H., H. Y. Inoue, and M. Ishii, 2002: Aircraft observation of carbon dioxide at 8-13 km altitude over the western Pacific from 1993 to 1999. Tellus, 54B, 1-21.

Messerschmidt, J., and Coauthors, 2011: Calibration of TCCON column-averaged $\mathrm{CO}_{2}$ : The first aircraft campaign over European TCCON sites. Atmos. Chem. Phys., 11, 10 76510777.

Moore, J. K., and O. Braucher, 2008: Sedimentary and mineral dust sources of dissolved iron to the world ocean. Bigeosciences, $\mathbf{5}$, 631-656.

— S. C. Doney, and K. Lindsay, 2004: Upper ocean ecosystem dynamics and iron cycling in a global three-dimensional model. Global Biogeochem. Cycles, 18, GB4028, doi:10.1029/ 2004GB002220.

Moss, R. H., and Coauthors, 2010: The next generation of scenarios for climate change research and assessment. Nature, 463, 747756, doi:10.1038/nature08823.

National Research Council, 2010: Verifying Greenhouse Gas Emissions: Methods to Support International Climate Agreements. National Academies Press, 124 pp.

Neale, R. B., J. Richter, S. Park, P. H. Lauritzen, S. J. Vavrus, P. J. Rasch, and M. Zhang, 2013: The mean atmospheric climate of the Community Atmosphere Model version 4 (CAM4) in forced SST and coupled experiments. J. Climate, in press.

Phillips, O. L., and Coauthors, 2009: Drought sensitivity of the Amazon rainforest. Science, 323, 1344-1347, doi:10.1126/ science.1164033.

Piao, S. L., and Coauthors, 2008: Net carbon dioxide losses of northern ecosystems in response to autumn warming. Nature, 451, 49-53.

Prentice, I. C., M. Heiman, and S. Sitch, 2000: The carbon balance of the terrestrial biosphere: Ecosystem models and atmospheric observations. Ecol. Appl., 10, 1553-1573.

Randerson, J. T., M. V. Thompson, T. J. Conway, I. Y. Fung, and C. B. Field, 1997: The contribution of terrestrial sources and sinks to trends in the seasonal cycle of atmospheric carbon dioxide. Global Biogeochem. Cycles, 11, 535-560.

- C. B. Field, I. Y. Fung, and P. P. Tans, 1999: Increases in early season ecosystem uptake explain recent changes in the seasonal cycle of atmospheric $\mathrm{CO}_{2}$ at high northern latitudes. Geophys. Res. Lett., 26, 2765-2768.

— geochemistry in coupled climate-carbon models. Global Change Biol., 15, 2462-2484, doi:10.1111/j.1365-2486.2009.01912.x.

Rayner, P. J., R. M. Law, and R. Dargaville, 1999: The relationship between tropical $\mathrm{CO}_{2}$ fluxes and the El Niño-Southern Oscillation. Geophys. Res. Lett., 26, 493-496.

Riahi, K., and Coauthors, 2011: RCP 8.5 a scenario of comparatively high greenhouse gas emissions. Climatic Change, 109, 33-57, doi:10.1007/s10584-011-0149-y.

Richardson, A., and Coauthors, 2012: Terrestrial biosphere models need better representation of vegetation phenology: Results from the North American Carbon Program Site Synthesis. Global Change Biol., 18, 566-584, doi:10.1111/ j.1365-2486.2011.02562.x.

Sabine, C. L., and Coauthors, 2004: The oceanic sink for anthropogenic $\mathrm{CO}_{2}$. Science, 305, 367-371, doi:10.1126/science.1097403.
Sarmiento, J. L., and N. Gruber, 2002: Sinks for anthropogenic carbon. Phys. Today, 55, 30-36.

_ , P. Monfray, E. Maier-Reimer, O. Aumont, R. J. Murnane, and J. C. Orr, 2000: Sea-air $\mathrm{CO}_{2}$ fluxes and carbon transport: A comparison of three ocean general circulation models. Global Biogeochem. Cycles, 14, 1267-1281.

Schuur, E. A. G., J. G. Voge, K. G. Crummer, H. Lee, J. O. Sickman, and T. E. Osterkamp, 2009: The effect of permafrost thaw on old carbon release and net carbon exchange from tundra. Nature, 459, 556-559.

Schwalm, C. R., C. A. Williams, K. Schaefer, I. Baker, G. J. Collatz, and C. Rodenbeck, 2011: Does terrestrial drought explain global $\mathrm{CO}_{2}$ flux anomalies induced by El Niño? Biogeosciences, 8, 2493-2506.

Smith, R. D., and Coauthors, 2010: The Parallel Ocean Program (POP) reference manual. Tech. Rep. LAUR-10-01853, Los Alamos National Laboratory, Los Alamos, NM, 141 pp. [Available online at http://www.cesm.ucar.edu/models/cesm1.1/ pop2/doc/sci/POPRefManual.pdf.]

Solomon, S., D. Qin, M. Manning, Z. Chen, M. Marquis, B. Averyt, M. Tignor, and H. L. Miller, Eds., 2007: Climate Change 2007: The Physical Science Basis. Cambridge University Press, 996 pp.

Stephens, B. B., and Coauthors, 2007: Weak northern and strong tropical land carbon uptake from vertical profiles of atmospheric $\mathrm{CO}_{2}$. Science, 316, 1732-1735.

Tans, P. P., I. Y. Fung, and T. Takahashi, 1990: Observational constraints on the global atmospheric $\mathrm{CO}_{2}$ budget. Science, 247, 1431-1438, doi:10.1126/science.247.4949.1431.

Taylor, J. A., and J. C. Orr, 1997: The pre-industrial latitudinal gradient of atmospheric $\mathrm{CO}_{2}$. Proc. Fifth Int. Carbon Dioxide Conf., Queensland, Victoria, Australia, CSIRO.

Thomson, A., and Coauthors, 2011: RCP 4.5: A pathway for stabilization of radiative forcing by 2100 . Climatic Change, 109, 77-94, doi:10.1007/s10584-011-0151-4.

Thornton, P. E., J.-F. Lamarque, N. A. Rosenbloom, and N. M. Mahowald, 2007: Influence of carbon-nitrogen cycle coupling on land model response to $\mathrm{CO}_{2}$ fertilization and climate variability. Global Biogeochem. Cycles, 21, GB4018, doi:10.1029/ 2006 GB002868.

— , and Coauthors, 2009: Carbon-nitrogen interactions regulate climate-carbon cycle feedbacks: Results from an atmosphere-ocean general circulation model. Biogeosciences, $\mathbf{6}$, 2099-2120.

Todd-Brown, K., and Coauthors, 2013: Causes of variation in soil carbon predictions from CMIP5 Earth system models and comparison with observations. Biogeosciences, 10, 1717-1736, doi:10.5194/bg-10-1717-2013.

Turnbull, J. C., and Coauthors, 2011: Atmospheric observations of carbon monoxide and fossil fuel $\mathrm{CO}_{2}$ emissions from East Asia. J. Geophys. Res., 116, D24306, doi:10.1029/2011JD016691.

van der Werf, G., and Coauthors, 2010: Global fire emissions and the contribution of deforestation, savanna, forest, agricultural, and peat fires (1997-2009). Atmos. Chem. Phys., 10, $11707-11735$.

van Vuuren, D., and Coauthors, 2011: The representative concentration pathways: An overview. Climatic Change, 109, 1-27.

Wang, S., J. K. Moore, F. W. Primeau, and S. Khatiwala, 2012: Simulation of anthropogenic $\mathrm{CO}_{2}$ uptake in the CCSM3.1 ocean-biogeochemical model: Comparison with data-based estimates. Biogeosciences, 9, 1321-1336.

Washenfelder, R. A., and Coauthors, 2006: Carbon dioxide column abundances at the Wisconsin tall tower site. J. Geophys. Res., 111, D22305, doi:10.1029/2006JD007154. 
Weijer, W., and Coauthors, 2012: The Southern Ocean and its climate in CCSM4. J. Climate, 25, 2652-2675.

WMO, 2011: 15th WMO/IAEA meeting of experts on carbon dioxide, other greenhouse gases, and related tracers measurements techniques. GAW Rep. 194/WMO TD 1553, 334 pp. [Avaialble online at http://www.wmo.int/pages/prog/arep/gaw/ documents/GAW_194_WMO_TD_No_1553_web_low_resol.pdf.]

Wofsy, S. C., and Coauthors, 2011: Hiaper Pole-to-Pole Observations (HIPPO): Fine-grained, global-scale measurements of climatically important atmospheric gases and aerosols. Philos. Trans. Roy. Soc., 369A, 2073-2086, doi:10.1098/rsta.2010.0313.
Wunch, D., and Coauthors, 2010: Calibration of the Total Carbon Column Observing Network using aircraft profile data. Atmos. Meas. Tech., 3,1351-1362.

, and Coauthors, 2011: The Total Carbon Column Observing Network. Philos. Trans. Roy. Soc., 369A, 2087-2112, doi:10.1098/ rsta.2010.0240.

Yang, Z., R. A. Washenfelder, G. Keppel-Aleks, N. Y. Krakauer, J. T. Randerson, P. P. Tans, C. Sweeney, and P. O. Wennberg, 2007: New constraints on Northern Hemisphere growing season net flux. Geophys. Res. Lett., 34, L12807, doi:10.1029/ 2007GL029742. 